\title{
Comprehensive in vivo identification of the c-Myc mRNA protein interactome using HyPR-MS
}

\author{
MICHELE SPINIELLO, ${ }^{1,2,3,4}$ MAISIE I. STEINBRINK, ${ }^{1,4}$ ANTHONY J. CESNIK, ${ }^{1}$ RACHEL M. MILLER, ${ }^{1}$ \\ MARK SCALF, ${ }^{1}$ MICHAEL R. SHORTREED, ${ }^{1}$ and LLOYD M. SMITH ${ }^{1}$ \\ ${ }^{1}$ Department of Chemistry, University of Wisconsin-Madison, Madison, Wisconsin 53706, USA \\ ${ }^{2}$ Department of Medicine of Precision, University of Studi della Campania Luigi Vanvitelli, Naples 80138, Italy \\ ${ }^{3}$ Division of Immuno-Hematology and Transfusion Medicine, Cardarelli Hospital, Naples 80131, Italy
}

\begin{abstract}
Proteins bind mRNA through their entire life cycle from transcription to degradation. We analyzed c-Myc mRNA protein interactors in vivo using the HyPR-MS method to capture the crosslinked mRNA by hybridization and then analyzed the bound proteins using mass spectrometry proteomics. Using HyPR-MS, 229 c-Myc mRNA-binding proteins were identified, confirming previously proposed interactors, suggesting new interactors, and providing information related to the roles and pathways known to involve c-Myc. We performed structural and functional analysis of these proteins and validated our findings with a combination of RIP-qPCR experiments, in vitro results released in past studies, publicly available RIP- and eCLIP-seq data, and results from software tools for predicting RNA-protein interactions.
\end{abstract}

Keywords: c-Myc; interactomics; proteomics; RNA-binding proteins

\section{INTRODUCTION}

Interactions between RNA-binding proteins (RBPs) and mRNAs are crucial for mRNA biology (Glisovic et al. 2008). mRNA molecules are associated with RBPs in mRNA ribonucleoprotein complexes (mRNPs) for their entire life-cycle, from transcription to degradation. The protein content of the mRNPs is subject to dynamic spatiotemporal remodeling and governs mRNA maturation, nuclear export, stability, localization, storage, translation, and degradation (Abdelmohsen and Gorospe 2015; Singh et al. 2015; Coppin et al. 2018). Alteration of the expression, sequence, posttranslational modifications, or binding cofactors of either an RBP or its mRNA regulatory sequence can disrupt normal interactions resulting in the formation of different mRNA splice forms or variation in translation rates, both of which have been linked to neurological, metabolic, and tumoral diseases (Audic and Hartley 2004; Kechavarzi and Janga 2014; Abdelmohsen and Gorospe 2015; Corbett 2018). Consequently, indepth characterization of specific mRNA-bound proteomes is essential to understanding mRNA biology in physiological and pathological conditions and to identifying new therapeutic targets.

${ }^{4}$ These authors contributed equally to this work.

Corresponding author: smith@chem.wisc.edu

Article is online at http://www.rnajournal.org/cgi/doi/10.1261/rna. 072157.119. Freely available online through the RNA Open Access option.
c-Myc is one of the most studied oncogenes. It produces a transcription factor that regulates the expression of many genes necessary for ribosomal and mitochondrial biogenesis, glucose, glutamine and lipid metabolism, cell cycle progression, differentiation, and apoptosis (Langa et al. 2001; Dang 2013; Kalkat et al. 2017). Given its broad functions, c-Myc gene expression is closely regulated at both transcriptional and posttranscriptional levels, and its protein activity is controlled via posttranslational modifications (Kalkat et al. 2017). c-Myc is therefore vulnerable to dysregulation through gene amplification, chromosome translocation, viral insertion, mRNA and protein destabilization, and variations in protein expression levels, each of which contribute to its involvement in more than half of human cancers (Bernasconi et al. 2000; Gabay et al. 2014; Kalkat et al. 2017). Activation of c-Myc can initiate and maintain many human tumors through the up-regulation of cellular growth mechanisms (Gabay et al. 2014). Thus, it is not surprising that periods of brief c-Myc suppression have been associated with tumor regression in different cancers. Many therapeutic strategies have been evaluated to achieve c-Myc inactivation by decreasing its expression or impairing its functionality at the gene, mRNA, or protein levels (Li et al. 2014).

(C) 2019 Spiniello et al. This article, published in RNA, is available under a Creative Commons License (Attribution 4.0 International), as described at http://creativecommons.org/licenses/by/4.0/. 
Numerous publications indicate the importance of posttranscriptional events, such as nuclear export, mRNA stability, translation, and degradation on the regulation of c-Myc expression through interactions between specific RBPs and c-Myc mRNA. For example, c-Myc mRNA nuclear export to the cytoplasm is regulated by the translation initiation factor elF4E (Tansey 2014). c-Myc mRNA stability can be variably regulated by ELAV1 (also named HuR), a member of the ELAV/Hu (embryonic lethal abnormal vision drosophila-like/Hu antigen) family, depending on specific cell types and conditions (Keene 2007; van Kouwenhove et al. 2011; Simone and Keene 2013). Additionally, the synergistic actions of IGF2BP1 and four associated proteins (HNRNPU, SYNCRIP, YBX1, and DHX9) provide stability to c-Myc mRNA at the coding region determinant (CRD) by restricting mRNA degradation processes (Weidensdorfer et al. 2009).

Regulation of c-Myc mRNA with specific RBPs can also occur at the translational level. CELF1 binding at the 3'-UTR negatively regulates c-Myc translation by preventing c-Myc mRNA from associating with ELAVL1 (Liu et al. 2015). Furthermore, two of the four c-Myc promoters, P1 and P2, produce transcripts with long 5' UTRs containing internal ribosomal entry sequences (IRESs). Proteins including hnRNPC, hnRNPK, PCBP1, PCBP2, hnRNPA1, and RPS25 are all able to modulate c-Myc mRNA translation by interacting with these IRESs (Evans et al. 2003; Kim et al. 2003; Audic and Hartley 2004; Shi et al. 2016). Alternatively, c-Myc mRNA degradation can be mediated by the cooperative action of two ribosomal proteins, RPL5 and RPL11, at its $3^{\prime}-$ UTR through recruitment of the RNAinduced silencing complex (miR-24/RISC complex) (Liao et al. 2014); a similar mechanism has been shown for RPS14 via a miR-145/RISC mediated pathway (Zhou et al. 2013). Its degradation can also be mediated by endonuclease activity of APE1 (Barnes et al. 2009). Finally, recent studies show that c-Myc mRNA degradation involves the attachment of CPEB to the cis element in the $3^{\prime}$-UTR of the c-Myc transcript and its interaction with the TOBCAF1 deadenylation complex (Ogami et al. 2014; Jolles et al. 2018).

These examples highlight the biological importance of the interactions between RBPs and c-Myc mRNA, suggesting this interface as a new target in cancer therapy (Koh et al. 2016). Such treatments have already been attempted with IRES inhibitors; normal interactions with RBPs are blocked, decreasing the rate of c-Myc translation and consequently reducing tumor survival in multiple myeloma, breast, and colorectal cancer models (Vaklavas et al. 2015; Wiegering et al. 2015; Shi et al. 2016).

Although studies have been able to reveal the interactions outlined above, technical limitations have prevented a comprehensive in vivo study of the c-Myc mRNA interacting proteome (Rissland 2017). Despite methods that have allowed capture of the polyadenylated mRNA-bound pro- teome (Ryder 2016) and MALAT1, NEAT1, and Xist IncRNA proteomes (West et al. 2014; Chu et al. 2015; McHugh et al. 2015), their high cost, complexity, and laborious nature have limited their widespread use (Marchese et al. 2016). We have developed HyPR-MS (hybridization purification of RNA-protein complexes followed by mass spectrometry) to address these issues by simplifying the capture oligonucleotide (CO) design, decreasing the degree of crosslinking and solubilization, and developing a multiplexed release strategy to allow the study of several RNA targets simultaneously. HyPR-MS has already been used to study the proteomes of unspliced full-length HIV RNA and MALAT1-001, NEAT1, and NORAD IncRNAs (Knoener et al. 2017; Spiniello et al. 2018). However, these applications targeted relatively abundant transcripts (>300 copies per cell) (Spiniello et al. 2018), while most RNAs have less than 50 copies per cell (Hanley et al. 2013). Transcripts with lower abundances are challenging to analyze because it is difficult to capture enough protein to meet mass spectrometer detection limits for complex mixtures, while still using a practical number of cells. Overcoming this challenge will facilitate the widespread adoption of in vivo RNA centric methods.

Here we extend the known lower capture limit of HyPR-MS to enable the study of the interacting proteome of c-Myc mRNA in K562 cells (60 copies per cell as estimated by RT-qPCR, see Materials and Methods). This chronic myelogenous leukemia (CML) system (K562) is particularly interesting given the role of c-Myc in leukemia tumorigenesis and specifically in CML progression (Vaqué et al. 2005; Delgado and León 2010; Albajar et al. 2011).

We identified 229 c-Myc interacting proteins using HyPR-MS. The c-Myc interactome encompasses RBPs with known or potential roles in transcription, maturation, transport, localization, stability, decay, and translation of c-Myc mRNA and folding of the nascent protein. Several technical and analytical parameters support the identified interactome, suggesting the utility of HyPR-MS as a tool to reveal the interactome of other mRNA targets at biologically relevant concentrations.

\section{RESULTS}

\section{HyPR-MS capture performance}

RT-qPCR was used to determine that c-Myc mRNA is present in approximately 60 copies per cell in K562 and small scale HyPR-MS experiments were performed using $5 \times$ $10^{5}$ cells to assess the necessary parameters for large-scale implementation (Supplemental Fig. S1). After this preliminary phase, three large scale HyPR-MS experiments were performed using $10^{8}$ cells, each with small aliquots taken to measure capture efficiency, specificity, release efficiency, and fold enrichment as indications of large-scale capture performance. These estimates of HyPR-MS efficacy 
compare c-Myc levels in the captured sample with three controls: an initial lysate sample prior to addition of COs, a sample containing nonspecific binders captured by a scrambled CO (not complementary to any part of the genome) after the c-Myc release, and a sample containing general polyadenylated mRNAs captured by a poly(dT) CO from a small aliquot of lysate. A brief depiction of the HyPR-MS procedure can be found in Supplemental Figure S2.

Capture efficiency is defined as the percent of mRNA target ultimately eluted from the beads compared to the amount of total target in the initial lysate control. These samples were analyzed using RT-qPCR assays corresponding to regions at the $5^{\prime}$ and $3^{\prime}$ ends of the c-Myc mRNA (Supplemental Fig. S5A), and the capture efficiency calculated based on $C_{t}$ values. The capture efficiency of c-Myc in the captured samples averaged $30 \%$ for each largescale experiment (Fig. 1A) mirroring the results of smallscale experiments and confirming that sufficient material had been captured for robust analysis via mass spectrometry (Supplemental Fig. S3A).

The stringency of each large-scale experiment was adjusted to provide high specificity for the captures. Specificity was calculated by comparing the ability of the c-Myc COs to selectively capture target mRNA while minimizing the capture of nontarget mRNAs. The amount of c-Myc in the captured sample was found to be at least 45-fold higher than that in the scrambled control sample for each end of the transcript (Fig. 1B, small-scale Supplemental Fig. S3B). c-Myc mRNA levels were also compared to GAPDH mRNA levels as a second measure of specificity (Supplemental Fig. S4).

The capture and release of oligonucleotides can interact with DNA as well as RNA targets. To ensure DNA-associated proteins did not contaminate the captured material, levels of DNA present in each captured sample were measured with qPCR. As shown in Figure 1A, the capture efficiency for c-Myc DNA is below $0.03 \%$, eliminating the
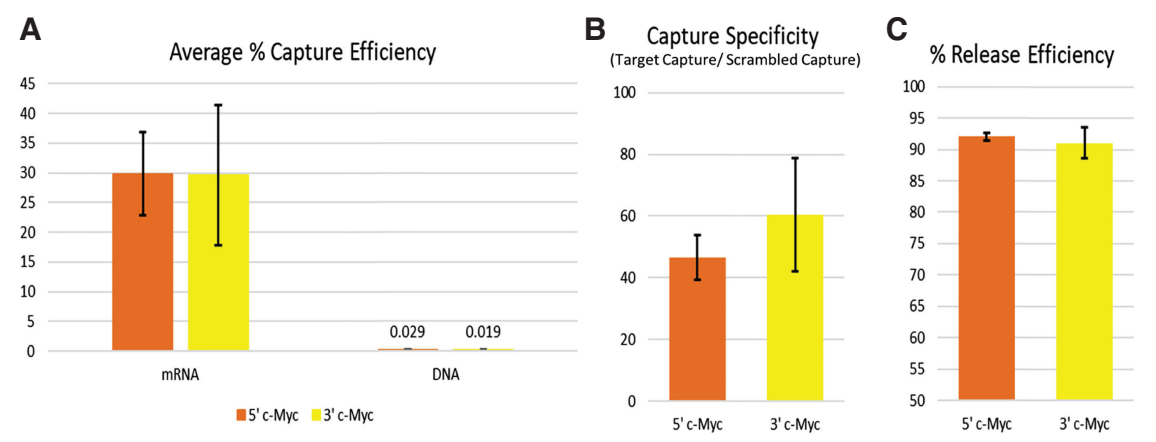

FIGURE 1. Measures of HyPR-MS large-scale efficacy. (A) Average capture efficiencies of all large-scale experiments based on RT-qPCR analysis. (B) Average capture specificities in large-scale experiments, comparing the amount of c-Myc target in the capture samples to that in the scrambled capture control samples. (C) Average release efficiencies of c-Myc targets from the magnetic beads in large-scale experiments. possibility of detecting DNA-associated protein contaminants by mass spectrometry.

Release efficiency indicates the degree of target elution from the beads, which affects both capture efficiency and specificity. Ideally, all targeted mRNA molecules would be released from the beads to achieve maximum capture efficiency, and minimal nonspecific targets would be released to achieve maximal capture specificity. Based on the RT-qPCR results, release efficiencies for $5^{\prime}$ and $3^{\prime}$ c-Myc regions were $92 \%$ and $91 \%$, respectively (Fig. 1C, small-scale Supplemental Fig. S3C).

\section{Characterization of the c-Myc protein interactome}

After release, proteins from each c-Myc captured, scrambled, poly(dT), and lysate samples were purified using eFASP (Erde et al. 2014) and digested with trypsin prior to mass spectrometry analysis. Two technical replicates of each biological replicate were analyzed by HPLC-ESI MS/MS. The LC-MS/MS results were normalized using MaxQuant software (version 1.5.3.30) (Cox and Mann 2008), and a finalized list of c-Myc mRNA-enriched proteins was compiled by comparing the captured protein lists with the scrambled, lysate, and poly(dT) controls and removing keratin- and biotin-related contaminants. Based on protein fold-enrichment, 229 proteins were identified as c-Myc interactors (Supplemental Table S1). We used Gene Ontology (GO) Term Enrichment to define each component of the interactome by terms relating to their molecular functions, cellular components, and biological processes (Supplemental Table S2).

The formaldehyde-based crosslinking conditions used in HyPR-MS stabilize both RNA-protein and proteinprotein interactions, allowing both direct and indirect protein interactors to be identified (Spiniello et al. 2018). Consequently, we expected to find enrichment of proteins with RNA-binding motifs and proteins that form complexes. GO analysis revealed that more than half of the identified interactors (132 of 229 proteins; $P$-value: $3.17 \times 10^{-76}$ ) are annotated with the molecular function "RNAbinding," while 53 proteins ( $P$-value: $\left.2.66 \times 10^{-06}\right)$ fall under the term "ribonucleotide binding" (Fig. 2; Supplemental Table S2). Protein-specific information from the UniProt database confirms that 46 c-Myc transcript interactors have documented RNA-binding domains (Supplemental Table S3; Zhang et al. 2010; Jankowsky and Harris 2015). The enrichment of cellular component GO terms, such as "protein-containing complex" (151 proteins; $P$-value: $4.23 \times 10^{-32}$ ), "ribonucleoprotein complex" (76 proteins; 


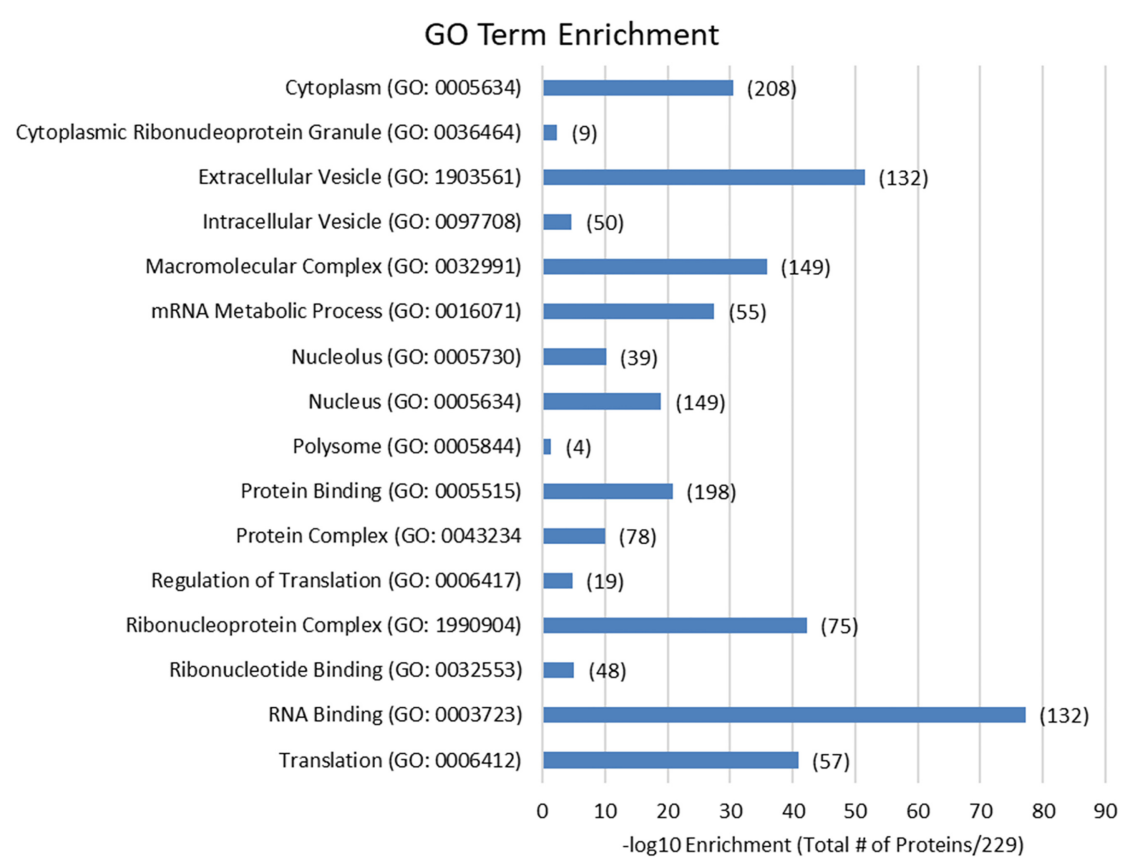

FIGURE 2. GO term enrichment results. Key GO terms are listed along with - $\log _{10}$ enrichment values and the total numbers of proteins with that GO term within the c-Myc enriched list. For all GO term results, see Supplemental Table S2.

$P$-value: $\left.1.03 \times 10^{-41}\right)$, and "cytoplasmic ribonucleoprotein granule" (12 proteins; $P$-value: $\left.1.49 \times 10^{-2}\right)$ suggests that many c-Myc RBPs interact with each other in mRNPs (Fig. 2; Supplemental Tables S2, S3). In fact, most mRNAs exist as components of mRNPs rather than as naked transcripts because the regulatory nature of these complexes allows the mRNA to fulfill its various posttranscriptional functions (Rissland 2017). Specifically, 65 proteins identified as c-Myc interactors are part of structural RNP complexes, including IGF2BP1-dependent mRNP granules, U1, U11/U12, U7 snRNPs, $40 \mathrm{~S}$ and $60 \mathrm{~S}$ ribosomal subunits, RISC, spliceosome $\mathrm{C}$, and tRNA-splicing ligase complexes (Supplemental Table S3).

Five of the c-Myc interacting proteins identified are already well-known c-Myc mRNA interactors: ELAVL1, IGF2BP1, PABPC1, RPL11, and RPS25 (Supplemental Table S3; Keene 2007; Weidensdorfer et al. 2009; van Kouwenhove et al. 2011; Simone and Keene 2013; Liao et al. 2014). Using STRING software (https://string-db.org/) and the BioGRID interaction repository database (https ://thebiogrid.org/), we were able to find proteins experimentally determined or predicted to interact with these five known interactors. These proteins represent new potential indirect c-Myc mRNA interactors, consistent with the propensity for RBPs to work together within mRNPs (Supplemental Table S3). Specifically, 36 c-Myc-enriched proteins are known interactors with ELAVL1 (Supplemental Table S4) and may comprise parts of the ELAV/Hu mRNA "regulon," a dynamic ribonucleoprotein structure postulated to posttranscriptionally regulate multiple functionally related mRNAs simultaneously, including the c-Myc transcript (Keene and Tenenbaum 2002; Keene 2007; Simone and Keene 2013). The GO analysis of these 36 proteins showed enriched GO terms relating to "protein-containing complex" (24 proteins; $P$-value: $4.14 \times 10^{-4}$ ), "ribonucleoprotein complex" (12 proteins; $P$-value: 1.83 $\left.\times 10^{-5}\right)$ and "RNA binding" (22 proteins; $P$-value: $2.30 \times 10^{-12}$ ) (Supplemental Table S4).

Following transcription, mRNAs may aid in maturation, transport and localization, stability maintenance, storage, degradation, and translation through the dynamic spatiotemporal remodeling of the associated mRNP structures (Abdelmohsen and Gorospe 2015; Singh et al. 2015; Coppin et al. 2018). Several c-Myc mRNA interacting proteins have a defined role in different aspects of mRNA processing such as $5^{\prime}$ end capping, reversible mRNA modification, splicing, $3^{\prime}$ end capping and polyadenylation, nuclear export, stability and decay, translation and folding of nascent proteins (Fig. 3). Encouragingly, GO terms related to maturation ("mRNA metabolic process," $P$-value: $3.16 \times 10^{-26}$ ), transport ("intracellular vesicle," $P$-value: $6.79 \times 10^{-03}$; "extracellular vesicle," $P$ value: $2.20 \times 10^{-49}$ ), localization ("nucleus," $P$-value 3.03 $\times 10^{-16}$; "cytoplasm," P-value: $2.77 \times 10^{-27}$; "nucleolus," $P$-value: $1.01 \times 10^{-09}$; "cytoplasmic ribonucleoprotein granule," $P$-value: $8.66 \times 10^{-03}$; "polysome," $P$-value: $1.79 \times 10^{-08}$ ) and translation ("regulation of translation," $P$-value: $5.84 \times 10^{-06}$; "translation," $P$-value: $4.75 \times 10^{-41}$ ) are enriched in the c-Myc list (Fig. 2; Supplemental Table S2), suggesting that HyPR-MS captured elements of the interacting proteome engaged in a variety of functions. Specifically, both nucleus and cytoplasm GO terms components are enriched (Supplemental Table S2), suggesting that the c-Myc mRNAs sample those locations (Pallavicini et al. 1994).

"Nucleolus" is also an enriched GO term with forty cMyc mRNA interacting proteins (Figs. 2, 3; Supplemental Tables S2, S3). A total of 53 (23.1\%) c-Myc RNA-interacting proteins have been previously identified via mass spectrometry as nucleolar constituents (Anderson et al. 2002; Scherl et al. 2002; Boisvert et al. 2011) (Supplemental Table S3), which is consistent with previous studies showing c-Myc mRNA accumulation in the nucleolus (Bond and Wold 1993; Bains et al. 1997; Ideue et al. 2004; Shimizu et al. 2007; Bártová et al. 2008, 2010). Most of 


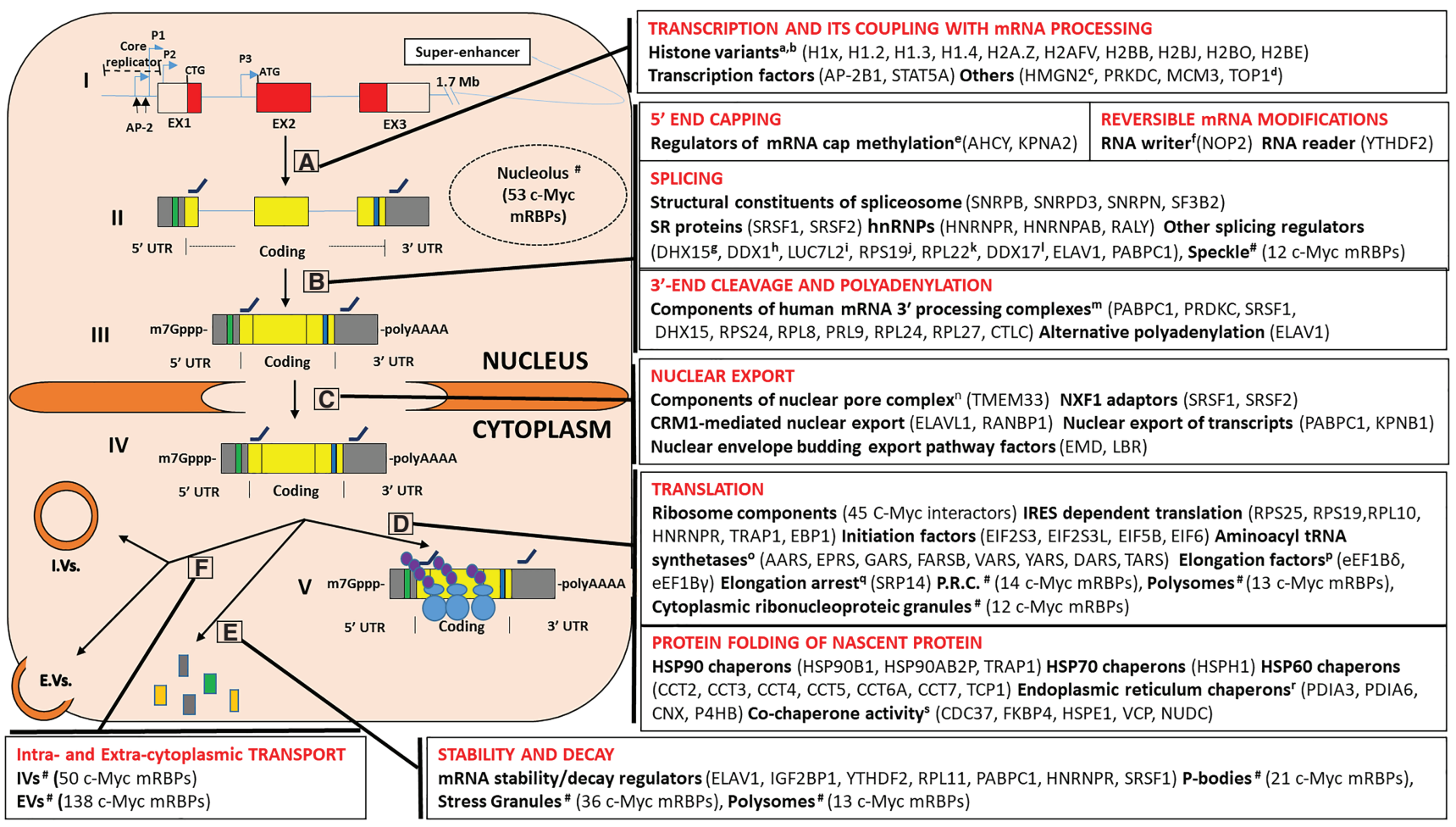

FIGURE 3. c-Myc mRNA processing and related HyPR-MS identified interactors. c-Myc processing, starting with the gene (I) and the following transcription into pre-mRNA (II), nuclear (III) and cytoplasmic (IV) mature mRNAs, and finally ending with mature mRNA immediately prior to translation. c-Myc RBPs identified using HyPR-MS are listed in boxes corresponding to specific phases of c-Myc mRNA processing, and some occur in multiple boxes if they are involved in several processing roles. (A) Transcription-related c-Myc proteins did not include canonical histones, but histone variants that replace canonical histones can impact processes such as transcription and RNA processing (Tolstorukov et al. 2012; Henikoff and Smith 2015; Buschbeck and Hake 2017; Talbert and Henikoff 2017). (B) Maturation, including 5' end capping, reversible mRNA modification, splicing and $3^{\prime}$ end cleavage and polyadenylation (C) Nuclear export (D) Translation (P.R.C. = perinuclear region of cytoplasm) and protein folding of the nascent protein (E) Stability and decay (F) Recent findings show vesicle-coupled transport for mRNP complexes in fungi, supporting the hypothesis of similar mechanisms of mRNA transport in higher eukaryotes (Jansen et al. 2014; Haag et al. 2015). In line with this, both IVs and EVs are enriched GO terms by gene ontology analysis (Supplemental Table S3). For proteins not explained in the text we refer

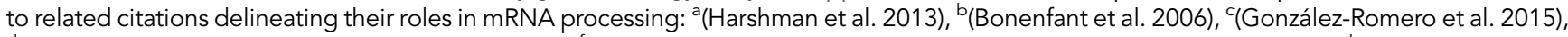

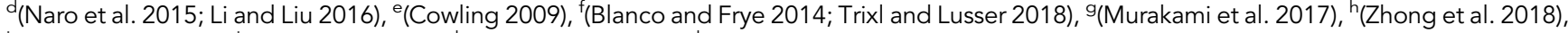
'(Singh et al. 2013), '(Orrù et al. 2007), k(Zhang et al. 2017), '(Dardenne et al. 2014), m(Shi et al. 2009), "'Kabachinski and Schwartz 2015), ${ }^{\circ}$ (Hausmann et al. 2007), P(Li et al. 2013), ' (Zhang and Shan 2012), r,s(Caplan 2003; Chen et al. 2005; Zheng et al. 2011; Saibil 2013; Halperin et al. 2014; Briones 2015; Gao et al. 2016; Narayanan et al. 2016). See Supplemental Table S3 for c-Myc RBPs belonging to these specific subgroups.

these nucleolar components are ribosomal proteins, and five are known components of the $40 \mathrm{~S}$ and 26 of the $60 \mathrm{~S}$ ribosomal complexes (Supplemental Table S3; van de Waterbeemd et al. 2018). Other c-Myc mRNA interacting nucleolar proteins are involved in ribosomal biogenesis (TOP1, FBL, EBNA1BP2, NOP56, and NOP58), are known translation factors (EIF6, SRP14) or are chaperones (CCT2, CCT5) (Scherl et al. 2002). This finding supports the hypothesis postulating that the nucleolus is the site of c-Myc mRNA translation (McLeod et al. 2014) and the place where the c-Myc protein is sequestered, modulating its availability for transcriptional activation or repression of target genes (Sanders and Gruppuso 2005).

Fourteen c-Myc interactors are located within the "perinuclear region of the cytoplasm" (Supplemental Table S3; Supplemental Figure 3), although this GO term does not appear among those enriched (Supplemental Table S2). c-Myc mRNA contains a perinuclear cytoplasmic localization signal within the $3^{\prime}$-UTR, which is thought to allow the fast and efficient import of c-Myc protein into the nucleus, where it acts as a transcription factor (Dalgleish et al. 2001). The term "polysome" is significantly enriched, comprising 13 c-Myc interactors (Figs. 2, 3; Supplemental Tables S2, S3) in agreement with the reported localization of c-Myc mRNA into polysomes (Hesketh et al. 1991; Chiluiza et al. 2011). Another enriched GO term, "extracellular vesicle" (EVs) (Figs. 2, 3), includes many c-Myc RBPs (138 of 229 proteins) (Fig. 2; Supplemental Table S2). EVs are important for pathological progression in disease states, especially in primary tumor growth and metastatic evolution, and they are responsible for transferring oncogenic molecules to other cells throughout the body 
(Sato-Kuwabara et al. 2015; Becker et al. 2016). Lipids, proteins, RNA, and DNA can all be involved in this process, including mRNA transcripts that encode transcription factors (Eirin et al. 2014; Soung et al. 2017); in particular, c-Myc mRNA has been identified in EVs from human medulloblastoma tumor cell lines (Balaj et al. 2014). Within the K562 cell line, EVs can transfer the BCR/ABL hybrid gene to normal neutrophils, promoting leukemic cancer progression (Cai et al. 2014). It is likely, given these findings, that c-Myc mRNA could also be present in EVs of K562 cells and promote cancer development.

\section{Known c-Myc RBPs identified by HyPR-MS}

Five previously noted c-Myc mRNA interactors were identified by HyPR-MS: IGF2BP1, ELAVL1, YTHDF2, RPL11, and RPS25. Specifically, IGF2BP1 together with HNRNPU, SYNCRIP, YBX1, and DHX9 (the latter three of which are present in our c-Myc captured proteins but did not meet the parameters for enrichment) form a coding region instability determinant (CRD)-associated regulatory complex (blue boxes within the transcripts depicted in Fig. 3) to prevent translation-coupled decay of c-Myc mRNA (Weidensdorfer et al. 2009). This stabilization process may occur by IGF2BP recruiting c-Myc transcripts into "protective" mRNPs or stress granules (Bley et al. 2015). ELAV1 can variably regulate c-Myc mRNA stability depending on specific cell types and conditions, either directly by binding AREs within the 3'-UTR of the c-Myc transcript (Fig. 3), or by cooperating with other proteins such as AGO2 or EIF4. (Keene 2007; Kim et al. 2009; Weidensdorfer et al. 2009; van Kouwenhove et al. 2011; Simone and Keene 2013). This is accomplished by alternative polyadenylation and splicing via competition for binding sites (Neve et al. 2017). YTHDF2, a N6-methyladenosine (m6A) "reader" protein, is a confirmed binder of c-Myc mRNA and is involved in increasing stability and expression of c-Myc in K562 cells, the same cells used in this study (Su et al. 2018). The m6A modification can be added to nascent transcripts during maturation events (Ke et al. 2017) and correlates with enhanced c-Myc mRNA translation (Hong 2018). RPL11 is involved in the regulation of c-Myc mRNA stability and promotes degradation by binding to the $3^{\prime}$-UTR and recruiting the RNAinduced silencing complex (miR-24/RISC complex) to the c-Myc transcript in response to ribosomal stress (Challagundla et al. 2011). Finally, RPS25 binds to c-Myc mRNA IRES and stimulates its activity during endoplasmic reticulum stress in multiple myeloma cells (Shi et al. 2016).

\section{New c-Myc RBPs identified by HyPR-MS}

Among the most interesting new c-Myc RBPs identified (Fig. 3A-D) are: the histone variant H2A.Z; transcription factors (AP-2B1, STAT5A); PRKDC; MCM3; structural constituents of the spliceosome (SNRPB, SNRPD3, SNRPN,
SF3B2); proteins with multiple functions in mRNA metabolism such as members of the SR family (SRSF1, SRSF2) and heterogeneous nuclear ribonucleoproteins (hnRNPs) (HNRNPR, HNRNPAB, and RALY); PABPC1; proteins involved in nuclear export mechanisms (RANBP1, KPNB1, EMD, LBR); IRES-mediated translation factors (RPS19, RPL10, TRAP1, EBP1); members of HSP90 (HSP90B1, HSP90AB2P, and TRAP1), HSP70 (HSPH1), HSP60 (CCT2, CCT3, СCT4, СCT5, ССT6A, СCT7, TCP1) and endoplasmic reticulum (PDIA6) chaperone families; and proteins with chaperone or cochaperone activity (VCP).

In accordance with the HyPR-MS findings, previous studies have reported an enrichment of H2A.Z at the c-Myc promoter. This is thought to up-regulate c-Myc transcription, in turn activating H2A.Z transcription in a positive feedback mechanism with tumorigenic consequences (Rangasamy 2010; Monteiro et al. 2014). H2A.Z is overexpressed in melanoma, intrahepatic cholangiocarcinoma, breast cancer, prostate cancer, and bladder cancer (Yang et al. 2018a). Furthermore, recent studies show a primary role for H2A.Z in coordinating transcription elongation and splicing (Santisteban et al. 2011; Nissen et al. 2017).

AP2B1, a member of the AP2 family, acts as either an oncogene or tumor suppressor in various human cancers (Yang et al. 2018b). Two different AP-2 binding sites are present at the c-Myc promoter (Fig. 3; Wierstra and Alves 2008), supporting AP2B1 as a c-Myc mRNA interactor and its potential involvement in c-Myc expression regulation. A second member of the AP2 family, STAT5A, is involved in cell proliferation, survival, and transformation and is a known regulator of c-Myc expression (Wierstra and Alves 2008). The identification of STAT5A as an interacting protein of c-Myc mRNA is supported by several recent studies (Pinz et al. 2016; Kalkat et al. 2017), where it was shown to link to the c-Myc super-enhancer, located 1.7 $\mathrm{Mb}$ downstream from its coding region (Fig. 3). During transcription, the super-enhancer can fold via chromatin looping to be in close proximity to the active promoter and nascent mRNA (Lee et al. 2015; Mora et al. 2016).

PRKDC is a serine/threonine-protein kinase involved in DNA double-stranded break repair and cell cycle control, impacting proper chromosome segregation during mitosis (Hsu et al. 2012). It has been suggested that PRKDC inhibition causes a down-regulation of c-Myc mRNA expression, decreasing protein levels and reducing c-Myc-driven proliferation (Zhou et al. 2014). This functional link is supported by the HyPR-MS results.

$\mathrm{MCM} 3$ is a component of the prereplication complex involved in eukaryotic genome replication; previous studies have shown it binds the $5^{\prime}$ replicator region of the c-Myc gene (Fig. 3; Ghosh et al. 2006). Furthermore, Snyder et al. (2009) have shown that MCM3 colocalizes with RNA polymerase II on the chromatin of transcribed genes, potentially acting with the other MCM proteins to unwind 
DNA during transcription elongation. The close proximity between the DNA and c-Myc mRNA transcription site during these processes could explain the observed MCM3 interaction with c-Myc mRNA, as cross-linking during HyPRMS could bind them together.

SNRPB, SNRPD3, SNRPN, and SF3B2 are structural constituents of the spliceosome: (Will and Lührmann 2011). SNRPB and SNRPD3 are Sm family proteins that are closely associated with RNA processing mechanisms and are constituents of critical RNA-associated small nuclear ribonucleoproteins (snRNPs); studies in yeast have shown that both SNRPB and SNRPD3, together with SNRPD1, interact directly with processed pre-mRNA at its $5^{\prime}$ splice site (Zhang et al. 2001). Similarly, SF3B2 is a subunit of the SF3b complex, which binds pre-mRNA at or near a branch site, anchoring the U2 snRNP to the transcript (Cretu et al. 2016).

Members of the SR and hnRNP families are the main mediators of splice site recognition (Busch and Hertel 2012). They play an important role in constitutive and alternative splicing regulation, interacting, respectively, with exonic splicing enhancers and exonic-intronic splicing silencers to recruit spliceosomal components to the pre-mRNA for splice site recognition (Long and Caceres 2009; Busch and Hertel 2012; Chabot and Shkreta 2016). Furthermore, SRSF1 and SRSF2 have been shown to work as adaptors in the Nxf1-driven pathway, used mostly for nuclear export of mRNAs (Delaleau and Borden 2015; Müller-McNicoll et al. 2016). HNRNPR modulates cap-independent translation rates in the cytosol by linking target mRNA IRESs (Geuens et al. 2016). Finally, HNRNPR and SRSF1 have been reported in mRNA stabilization (Lemaire et al. 2002; Sun et al. 2011; Cappelli et al. 2018) and could play this role for c-Myc transcripts as well.

PABPC1 can regulate $3^{\prime}$ mRNA alternative cleavage, polyadenylation and hyperadenylation (Kumar and Glaunsinger 2010; Li et al. 2015). It is also known to bind "stability sequences" such as AREs, poly(A) tails, and CRD that are all present on the c-Myc transcript (Fig. 3; Laird-Offringa et al. 1989; Lemm and Ross 2002; Gorgoni and Gray 2004). Furthermore, PABPC1 can inhibit enzymes during $3^{\prime}-5^{\prime}$ mRNA decay that use deadenylase activity to remove the poly(A) tail and subsequently degrade the remaining exome (Brewer 1999; Garneau et al. 2007). These are the main players suggested to be involved in Myc transcript degradation. Finally, PABPC1 may interact with c-Myc mRNA during nuclear export, as has been suggested for other transcripts (Mangus et al. 2003).

Several other identified c-Myc mRNA interactors are also associated with nuclear export. RANBP1, along with ELAVL1, acts within the CRM1-mediated pathway to export the mRNAs of proto-oncogenes containing AREs in their 3'-UTR (Köhler and Hurt 2007; Delaleau and Borden 2015), all characteristics exhibited by c-Myc transcripts (Fig. 3). Specifically, ELAV1 binds AREs and associates with CRM1 while RNABP1 permits the release of the mRNA into the cytoplasm (Delaleau and Borden 2015). Although CRM1 is not present in our list, another karyopherin, KPNB1, was identified by HyPR-MS as a c-Myc mRNA interactor and is able to export mRNAs from the nucleus in the cytoplasm (Yi et al. 2002), making it an interesting candidate for involvement in c-Myc mRNA nuclear export. EMD and LBR are two constituents of the inner nuclear membrane proposed to have a role in the nuclear envelope budding pathway (Strambio-De-Castilla 2013), an alternative nuclear export pathway for mRNAs or large mRNPs (Delaleau and Borden 2015). Instances of nuclear envelope budding have been described for herpes virus capsids and mRNP complexes in Drosophila larval body wall muscles; in both cases, protein kinase C (PKC) phosphorylates nuclear lamina, initiating the envelope budding process (Speese et al. 2012). Interestingly, a previous study has shown that PKC inhibitors prevent c-Myc transcript nuclear export, causing nuclear accumulation in peripheral blood mononuclear cells (Selvatici et al. 1998). These studies suggest a potential budding pathway for c-Myc mRNP nuclear export.

RPS19 and RPL10 are ribosomal proteins involved in IRES-mediated translation of mRNAs, affecting erythroid differentiation and BCL-2 transcript, respectively (Horos et al. 2012; Kampen et al. 2019). TRAP1 promotes IRESdependent translation and attenuates cap-mediated translation; down-regulation of TRAP1 has been associated with lower c-Myc protein levels (Matassa et al. 2014), suggesting it regulates IRES-dependent c-Myc translation. Finally, EBP1 is known to interact with IRES of the footand-mouth disease virus, and its expression in K562 is functionally related with cell proliferation, acting on rRNA synthesis and proliferating cell nuclear antigen levels (Monie et al. 2007; Nguyen le et al. 2016). Our finding by HyPR-MS that EBP1 binds c-Myc mRNA suggests EBP1 could promote $\mathrm{K} 562$ cell proliferation by regulating c-Myc mRNA expression and specifically its translation initiation. This result and suggested functional importance is in line with previous studies reporting that most of c-Myc translation initiation occurs via the interaction of canonical and IRES-trans-acting factors (ITAFs) with an IRES sequence in the $5^{\prime}$ UTR region of c-Myc transcript (Fig. 3; Stoneley et al. 2000; Cobbold et al. 2010). Only a few initiation factors are present in our list: EIF2S3, EIF2S3L, EIF5B, and EIF6. This makes sense if we consider that several in vitro and in vivo studies show IRES-mediated translation can start with or without a limited set of translation initiation factors, ensuring direct and efficient ribosome recruitment (López-Lastra et al. 2005; Deniz et al. 2009; Johnson et al. 2017).

Members of the HSP90 protein family are known to be involved in the maturation of oncogenic proteins (Chen et al. 2005; Saibil 2013). CDC37, which is able to direct HSP90 proteins to the target protein and modulate their 
functions, was found to cooperate with c-Myc in tumor transformation in several tissue types (Stepanova et al. 2000; Saibil 2013). HSPH1 is known to bind c-Myc proteins in aggressive B-cell lymphomas, modulating c-Myc expression by preventing its degradation via its chaperone activity. In vitro and in vivo studies show that HSPS1 inhibitors down-regulate c-Myc expression, significantly decreasing cell proliferation and tumor growth in B cell lymphomas (Briones 2015). The identification of HSPH1 as a c-Myc mRNA interactor in K562 cells suggests a similar relationship and may indicate the utility to therapeutically target this heat-shock protein in c-Myc driven lymphomas. Seven of the nine members of the HSP60 protein family of chaperonins (Fig. 3D) are found in our list due to their role in c-Myc protein folding (Narayanan et al. 2016; Carr et al. 2017). Finally, PDIA6 and VCP can modulate c-Myc protein levels in bladder and osteosarcoma cancer cells, respectively (Cheng et al. 2017; Heidelberger et al. 2018).

\section{Confirmation and validation of the HyPR-MS identified c-Myc mRNA protein interactome}

The measurements of capture efficiency and specificity, along with release efficiency (Fig. 1) show the technical efficacy of the HyPR-MS method. The number and types of RBPs identified by HyPR-MS also represent an analytical validation of the results: $91.2 \%$ (209/229) of proteins are involved in known aspects of mRNA processing, 67.2\% (154/ 229) contain structural motifs characteristic of RBPs and/or mRNPs components, 39.7\% (91/229) are defined interactors with known c-Myc mRNA binders, and 6.1\% (14/229) are functionally involved in c-Myc transcript or nascent c-Myc protein processing. Supplemental Table S5 lists all the proteins identified in each of these groups and the analytical parameters used to classify them. Only 15 (6.5\%) proteins are not present in any of these groups (Supplemental Table S5).

We validated 28 of the identified c-Myc mRNA interacting proteins by comparing our data with (a) well defined c-Myc mRNA interactors from published manuscripts (b) potential binders by in vitro methods, (c) predicted partners using dedicated software, (d) publicly available eCLIP-seq data, and finally (e) directly through RIP-qPCR experiments (Fig. 4; Supplemental Table S5). These validation results further support the ability of HyPR-MS to identify real RBPs for a specific target RNA molecule.

\section{Literature identification of c-Myc interactors}

Through literature analysis, five previously confirmed c-Myc mRNA interactors were identified in our enriched list: ELAVL1, IGF2BP1, YTHDF2, RPS25, and RPL11 (Keene 2007; Weidensdorfer et al. 2009; van Kouwenhove et al. 2011; Simone and Keene 2013; Liao et al. 2014; Su et al. 2018).

\section{Literature identification of possible c-Myc interactors}

Fifteen HyPR-MS c-Myc RBPs were previously identified as potential c-Myc IRES interactors using in vitro methods. Specifically, PABPC1 and EIF2S3 together with proteins forming the 40S (RPS18, RPS2, RPS9, RPS19, RPS6, RPS20) and 60S (RPLP0, RPL12, RPL13, RPL3, RPL18) ribosomal complexes were identified on a c-Myc IRES construct in native $48 \mathrm{~S}$ initiation complexes that were subjected to glutathione RNA affinity chromatography purification and mass spectrometry analysis (Thoma et al. 2008). Furthermore, two HyPR-MS-identified proteins, DDX1 and ELAVL1, were previously noted as potential cMyc mRNA interactors using a protein microarray system (Siprashvili et al. 2012; Marchese et al. 2016).

\section{Use of software to predict c-Myc interactors}

Recently developed prediction software RBPDB (http ://rbpdb.ccbr.utoronto.ca/) and RBPmap (http://rbpmap .technion.ac.il/) are able to predict the presence and location of binding sites between RNA molecules and a selected pool of RNA-binding proteins (Cook et al. 2011; Paz et al. 2014). These programs have been used to determine whether c-Myc mRNA has binding sites for proteins identified as mRNA interactors using HyPR-MS. c-Myc mRNA contains predicted binding sites for several RNA-binding proteins identified here, implying they are direct interactors with exact binding locations and further supporting the utility of HyPR-MS (Supplemental Tables S6, S7). In addition to the previously mentioned ELAVL1 and PABPC1, RBPDB and RBPmap software both detected SRSF1 and SRSF2 as potential interactors. RBPmap additionally predicted RALY to be a c-Myc-associated protein. Each of

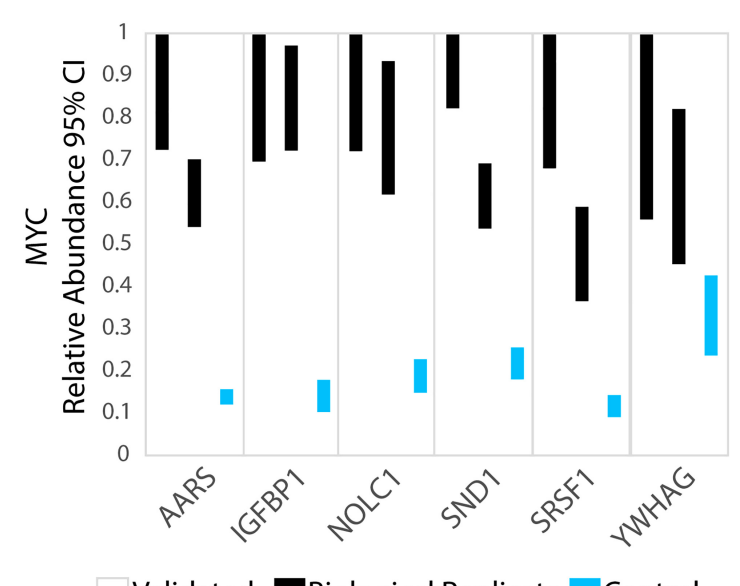

Validated Biological Replicate $\square$ Control

FIGURE 4. Validation of AARS, IGFBP1, NOLC1, SND1, SRSF1, and YWHAG binding of c-Myc mRNA using publicly available eCLIP data (Supplemental Fig. S6). The 95\% credibility intervals for c-Myc mRNA abundances are higher in all eCLIP pull-downs than in the control experiments performed without cross-linking. 
these proteins is involved in mRNA processing as described previously.

\section{Analysis of CLIP-seq data}

Publicly available eCLIP-seq data from K562 or HepG2 cells was used to confirm c-Myc mRNA interactors present in our list. In addition to the already cited IGF2BP1 and SRSF1, these results validated AARS, NOLC1, YWHAG, and SND1 as c-Myc-mRNA interactors (Fig. 4).

\section{RIP-ChIP validation}

Finally, two proteins within the c-Myc enriched list, histone variant H1F0 and Myb-binding protein 1A (MYBBP1A), were experimentally confirmed as c-Myc mRNA interactors by RIP-qPCR analysis compared to an IgG negative control (Fig. 5). Interestingly, an increased expression of H1.X has been found in neuroendocrine tumors (Warneboldt et al. 2008), many of which are driven by c-Myc deregulation (Farrell et al. 2017; Mollaoglu et al. 2017). MYBBP1A, a transcription regulator involved in cell division, cell proliferation and apoptosis (Mori et al. 2012; George et al. 2015), is able to stimulate c-Myc transcription inhibiting c-Myb (Yamauchi et al. 2008). Furthermore, MYBBP1A can bind RNA molecules as the IncRNA PURPL via the adaptor protein HuR, which is also present in our list, forming a complex that regulates p53 protein stability in the nucleoplasm (Li et al. 2017).

\section{DISCUSSION}

To our knowledge, this is the first work that identifies a specific mRNA-bound proteome using an in vivo RNA-centric method. The choice of c-Myc mRNA (60 copies per cell in K562) as the target of our study represents a test of

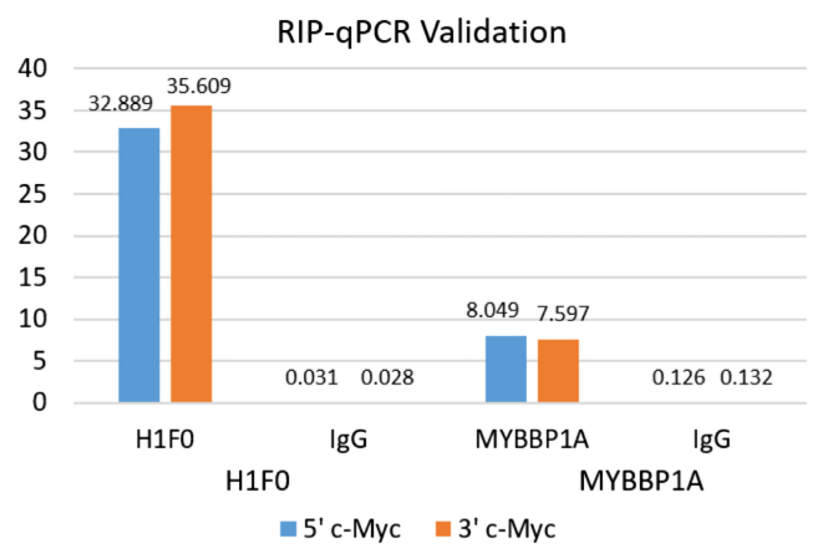

FIGURE 5. RIP-qPCR validation for H1FO and MYBBP1A. RIP-qPCR was performed to validate the enrichment of histone variant $\mathrm{H} 1 \mathrm{FO}$ and transcription regulator MYBBP1A with c-Myc in K562 cells. Fold enrichments were calculated using the $\Delta \Delta C_{t}$ method as described in the kit protocol. the ability of HyPR-MS to identify the interacting proteomes of RNAs present at biologically relevant concentrations while still using a reasonable $\left(10^{8}\right)$ number of cells. Furthermore, the regulation of c-Myc expression can happen posttranscriptionally (Sears 2004), and consequently, the comprehensive identification of c-Myc mRNA-protein interactions gives us new insights into the RBPs involved in regulating one of the most important oncogenes, potentially revealing new therapeutic targets.

Using HyPR-MS, we identified 229 c-Myc RBPs, confirming previously proposed interactors, suggesting new interactors, and providing information related to the roles and pathways involving c-Myc. Future functional studies are necessary to test the role of c-Myc mRNA interactors identified here and their impact on $c-M y c$ gene expression.

The high capture efficiency and specificity support the efficacy of HyPR-MS pulldowns for the c-Myc transcript. The toehold-mediated release strategy permits copurification of the poly(dT) and scrambled capture probes consecutively with that of c-Myc and thereby allows them to be used as negative controls to assist in data analysis and interpretation. Structural and functional analysis (gene ontology, UniProt, STRING, bioGRID, and previous MS-based studies) confirm the reliability of the identified c-Myc RBPs. Five of these (ELAVL1, IGF2BP1, YTHDF2, RPS25, and RPL11) are known interactors with defined roles in cMyc mRNA processing. Others were validated by comparing our findings with previous in vitro results, publicly available RIP- and eCLIP-seq data, software predictions, or RIPqPCR experiments.

Together, these analyses have identified a comprehensive binding proteome for c-Myc mRNA, revealing new insights into its interaction partners. This has uncovered candidates for potential new therapies focusing on one of the most biologically relevant but difficult to drug oncogenes, and demonstrates the power of HyPR-MS to study mRNAs at biologically significant levels.

Future applications of HyPR-MS to the study of misspliced transcripts and/or to the comparison between the interacting proteomes of individual RNA targets in physiological and pathological conditions could permit the identification of RNA-protein interactions "ideal" for the development of effective, specific therapies while limiting off-target effects.

\section{MATERIALS AND METHODS}

\section{Cell culture and growth conditions}

K562 cells were cultured in suspension with DMEM medium containing $10 \%$ fetal bovine serum (FBS) and 1\% penicillin/streptomycin at $37^{\circ} \mathrm{C}$ and $5 \% \mathrm{CO}_{2}$. Crosslinking was performed with $1 \%$ formaldehyde $(\mathrm{w} / \mathrm{v})$ for $10 \mathrm{~min}$ at room temperature, then quenched with Tris- $\mathrm{HCl}(\mathrm{pH} 8.0)$ at a final concentration of 250 $\mathrm{mM}$ for $10 \mathrm{~min}$. Cells were washed with cold phosphate buffered 
saline (PBS) twice, then pelleted by centrifugation at $4^{\circ} \mathrm{C}$ and flash frozen in liquid nitrogen and stored at $-80^{\circ} \mathrm{C}$ prior to use.

\section{HyPR-MS method}

Lysis of formaldehyde-crosslinked $\mathrm{K} 562$ cells, sonication of the resulting lysate, hybridization capture, and bead release were performed as described previously (Spiniello et al. 2018). Briefly, biotinylated c-Myc mRNA, poly(dT) and scrambled capture DNA oligonucleotides (COs) are added to the sonicated lysate and hybridize with their respective RNA targets to create $\mathrm{CO}$ mRNA-protein complexes. After hybridization, streptavidin-modified magnetic beads are added and bind the biotinylated COs to create bead-CO-mRNA-protein complexes. A magnetic Eppendorf rack separates these complexes out of solution so nontarget RNA and proteins can be removed. Following this, release DNA oligonucleotides (ROs) complementary to each $\mathrm{CO}$ are sequentially added to specifically elute the target RNA-protein complexes back into solution for collection. Small aliquots can be reverse transcribed and analyzed via RT-qPCR at various stages of the procedure to test measures of method efficiency, while larger samples can be subjected to protein purification and mass spectrometric analysis. All CO and RO sequences and large-scale concentrations are included in Supplemental Information (Supplemental Fig. S5B).

\section{RT-qPCR}

Following HyPR-MS, proteinase $\mathrm{K}$ treatment, RNA purification and RT-qPCR were performed on small aliquots of cell lysate, purified target captures, and post-release beads as described in Spiniello et al. (2018) to estimate transcript copy numbers, capture and release effciencies, and capture specificities. Estimation of c-Myc copy number within the K562 cell line was based on standard curves prepared using genomic DNA (G3041, Promega) using the method described previously (Nolan et al. 2006; Yun et al. 2006). All assay sequences are included in the Supplemental Information (Supplemental Fig. S5C).

\section{Protein purification and mass spectrometry of peptides}

Larger aliquots containing high amounts of c-Myc-, scrambled-, poly(dT)-, and lysate-associated proteins were purified using eFASP and digested with trypsin as described by Spiniello et al. (2018). Briefly, lysate, c-Myc, poly(dT) and scrambled samples were washed through $50 \mathrm{kD}$ centrifugal filters to collect the proteins. These proteins were then washed with an exchange buffer (urea, deoxycholic acid), reducing buffer (urea, dithiothreitol), alkylation buffer (urea, iodoacetamide, ammonium bicarbonate), and digestion buffer (urea, ammonium bicarbonate, deoxycholic acid). Proteins were digested with $1 \mu \mathrm{g}$ trypsin overnight at $37^{\circ} \mathrm{C}$ and then eluted from the filter. These solutions were washed with ethyl acetate and TFA before lyophilization via SpeedVac. Each sample was reconstituted in formic acid solution and analyzed in triplicate (three technical replicates for each of the three biological replicates) by HPLC-ESI-MS/MS as performed in Spiniello et al. (2018), except for using ten MS/ MS HCD scans of the ten highest intensity parent ions instead of twenty.

\section{Mass spectrometry data processing}

Raw files from the mass spectrometry output for c-Myc mRNA, poly(dT), scrambled and lysate trypsin-digested samples were analyzed using MaxQuant software (http://www.biochem.mpg.de/ 5111795/maxquant), as described in Spiniello et al. (2018). A protein was ultimately considered to be enriched in the c-Myc mRNA capture samples if its intensity was $\geq 5$-fold greater in the c-Myc mRNA sample than in the scrambled capture sample, lysate, or poly(-dT) sample. Only proteins meeting this criterion in at least two of the three biological replicates were considered enriched for c-Myc transcript capture. Proteins related to keratinization and biotin were removed from this list as likely contaminants. The final lists were then analyzed to confirm already established biological functions and to predict new characteristics for each target.

\section{Interactome data analysis}

Gene Ontology (GO) Enrichment Analysis was performed using the publicly available Gene Ontology Consortium (http://www .geneontology.org/) (Ashburner et al. 2000; The Gene Ontology Consortium 2019). The enriched proteome list associated with c-Myc mRNA was used as input for GO Enrichment Analysis (PANTHER Overrepresentation Test released 12/5/2017; GO Ontology database released 12/27/2017; Reference all genes in Homo sapiens database; FISHER test type) to search for GO terms related to biological process, molecular function, and cellular component.

Protein relationships were explored using the multiple protein search feature in the STRING (https://string-db.org/) (Szklarczyk et al. 2017) and BioGRID (https://thebiogrid.org/) (Oughtred et al. 2019) databases and protein domains were identified using the UniProt database (https://www.uniprot.org/) (The UniProt Consortium 2019).

\section{RIP-ChIP validation}

RIP-ChIP was used to validate the interactions of c-Myc mRNA with MYBBP1A and H1F0 proteins. Antibodies for each were purchased (Anti-MYBBP1A: Novus Biologicals NB100-61050; Anti$\mathrm{H} 1 \mathrm{x}$ : Bethyl Laboratories A304-603A) and used in conjunction with the EZ-Magna Nuclear RIP (Cross-Linked) Nuclear RNA-Binding Protein Immunoprecipitation Kit (EDM Millipore Cat. No. 1710521). Normal rabbit IgG was purchased through EDM Millipore (Cat. No. 12-370). K562 cells were crosslinked with 1\% formaldehyde for $10 \mathrm{~min}$, lysed, and sonicated. Immunoprecipitation, elution, and RNA purification were performed as indicated by the EZMagna kit protocol, and DNase I digestion was carried out after these steps (optional DNase I treatment of the sheared crosslinked chromatin was excluded). RT-qPCR was performed as described above, and the $\Delta \Delta C_{t}$ method was used for data analysis as detailed at the end of the kit protocol to calculate fold enrichment above IgG. Fold enrichments exceeding two were considered significant. 


\section{Validation of Myc-binding proteins using eCLIP data}

Several binding proteins for c-Myc mRNA were validated using eCLIP immunoprecipitation data from the ENCODE project in either K562 or HepG2 against each binding protein (The ENCODE Project Consortium 2012). The RNAs captured in these pulldowns were quantified using the integrated software solution Spritz (https://github.com/smith-chem-wisc/Spritz) using the "quantify" command, which quantifies genes and transcripts using RSEM (Li and Dewey 2011). First, Spritz prepares reference indices for the STAR (Dobin et al. 2013) alignment software and RSEM quantification software using the human reference genome (GRCh38.81). Then, it downloads FASTQ files from Sequence Read Archive accessions, if available, and calculates gene abundances using RSEM. The parameters used for the "rsem-calculate-expression" program within RSEM were "-time -calc-ci star -num-threads 24 -output-genome-bam -paired-end," and this analysis was performed on an Intel Xeon CPU with 24 cores and $128 \mathrm{~GB}$ of RAM. These computations took about $9 \mathrm{~h}: 1 \mathrm{~h}$ for aligning reads, $2 \mathrm{~h}$ for estimating expression levels, and $6 \mathrm{~h}$ for calculating the credibility intervals of the expression levels.

\section{SUPPLEMENTAL MATERIAL}

Supplemental material is available for this article.

\section{ACKNOWLEDGMENTS}

Work for this manuscript was funded by National Institutes of Health-National Cancer Institute (NIH-NCl) grant R01CA193481. We thank Dr. Katie Buxton and Dr. Lei Lu for assistance with cell culture.

Received May 26, 2019; accepted June 27, 2019.

\section{REFERENCES}

Abdelmohsen K, Gorospe M. 2015. Noncoding RNA control of cellular senescence. Wiley Interdiscip Rev RNA 6: 615-629. doi:10 .1002/wrna.1297

Albajar M, Gómez-Casares MT, Llorca J, Mauleon I, Vaqué JP, Acosta JC, Bermúdez A, Donato N, Delgado MD, León J. 2011. MYC in chronic myeloid leukemia: induction of aberrant DNA synthesis and association with poor response to imatinib. Mol Cancer Res 9: 564-576. doi:10.1158/1541-7786.MCR-10-0356

Andersen JS, Lyon CE, Fox AH, Leung AK, Lam YW, Steen H, Mann M, Lamond Al. 2002. Directed proteomic analysis of the human nucleolus. Curr Biol 12: 1-11.

Ashburner M, Ball CA, Black JA, Botstein D, Butler H, Cherry JM, Davis AP, Dolinski K, Dwight SS, Eppig JT, et al. 2000. Gene ontology: tool for the unification of biology. Nat Genet 25: 25-29. doi:10.1038/75556

Audic Y, Hartley RS. 2004. Post-transcriptional regulation in cancer. Biol Cell 96: 479-498. doi:10.1016/j.biolcel.2004.05.002

Bains MA, Giles I, Wright DH. 1997. Distribution and configuration of c-myc RNA during transcriptional attenuation in differentiating cells in-situ. Histochem Cell Biol 107: 259-263. doi:10.1007/ s004180050111

Balaj L, Momen-Heravi F, Chen W, Sivaraman S, Zhang X, Ludwig N, Meese E, Wurdinger T, Noske D, Charest A, et al. 2014. Detection of human c-MYC and EGFR amplifications in circulating extracellular vesicles in mouse tumour models. J Circ Biomark 3: 6. doi:10 $.5772 / 59174$

Barnes T, Kim WC, Mantha AK, Kim SE, Izumi T, Mitra S, Lee CH. 2009. Identification of Apurinic/apyrimidinic endonuclease 1 (APE1) as the endoribonuclease that cleaves c-myc mRNA. Nucleic Acids Res 37: 3946-3958. doi:10.1093/nar/gkp275

Bártová E, Harnicarová A, Krejcí J, Strasák L, Kozubek S. 2008. Singlecell c-myc gene expression in relationship to nuclear domains. Chromosome Res 16: 325-343. doi:10.1007/s10577-007-1196-0

Bártová E, Horáková AH, Uhlírová R, Raska I, Galiová G, Orlova D, Kozubek S. 2010. Structure and epigenetics of nucleoli in comparison with non-nucleolar compartments. J Histochem Cytochem 58: 391-403. doi:10.1369/jhc.2009.955435

Becker A, Thakur BK, Weiss JM, Kim HS, Peinado H, Lyden D. 2016. Extracellular vesicles in cancer: cell-to-cell mediators of metastasis. Cancer Cell 30: 836-848. doi:10.1016/j.ccell.2016.10.009

Bernasconi NL, Wormhoudt TA, Laird-Offringa IA. 2000. Post-transcriptional deregulation of myc genes in lung cancer cell lines. Am J Respir Cell Mol Biol 23: 560-565. doi:10.1165/ajrcmb.23.4 .4233

Blanco S, Frye M. 2014. Role of RNA methyltransferases in tissue renewal and pathology. Curr Opin Cell Biol 31: 1-7. doi:10.1016/j .ceb.2014.06.006

Bley N, Lederer M, Pfalz B, Reinke C, Fuchs T, Glaß M, Möller B, Hüttelmaier S. 2015. Stress granules are dispensable for mRNA stabilization during cellular stress. Nucleic Acids Res 43: e26. doi:10.1093/nar/gku1275

Boisvert FM, Ahmad Y, Gierliński M, Charriére F, Lamont D, Scott M, Barton G, Lamond Al. 2012. A quantitative spatial proteomics analysis of proteome turnover in human cells. Mol Cell Proteomics 11: M111.011429. doi:10.1074/mcp.M111.011429

Bond VC, Wold B. 1993. Nucleolar localization of myc transcripts. Mol Cell Biol 13: 3221-3230. doi:10.1128/MCB.13.6.3221

Bonenfant D, Coulot M, Towbin H, Schindler P, van Oostrum J. 2006. Characterization of histone $\mathrm{H} 2 \mathrm{~A}$ and $\mathrm{H} 2 \mathrm{~B}$ variants and their posttranslational modifications by mass spectrometry. Mol Cell Proteomics 5: 541-552. doi:10.1074/mcp.M500288-MCP200

Brewer G. 1999. Evidence for a 3'-5' decay pathway for c-myc mRNA in mammalian cells. J Biol Chem 274: 16174-16179. doi:10.1074/ jbc.274.23.16174

Briones J. 2015. Heat-shock proteins: a c-Myc lymphoma target? Blood 125: 1685-1686. doi:10.1182/blood-2015-01-622191

Busch A, Hertel KJ. 2012. Evolution of SR protein and hnRNP splicing regulatory factors. Wiley Interdiscip Rev RNA 3: 1-12. doi:10 $.1002 /$ wrna. 100

Buschbeck M, Hake SB. 2017. Variants of core histones and their roles in cell fate decisions, development and cancer. Nat Rev Mol Cell Biol 18: 299-314. doi:10.1038/nrm.2016.166

Cai J, Wu G, Tan X, Han Y, Chen C, Li C, Wang N, Zou X, Chen X, Zhou F, et al. 2014. Transferred BCR/ABL DNA from K562 extracellular vesicles causes chronic myeloid leukemia in immunodeficient mice. PLoS ONE 9: e105200. doi:10.1371/journal.pone.0105200

Caplan AJ. 2003. What is a co-chaperone? Cell Stress Chaperones 8: 105-107. doi:10.1379/1466-1268(2003)008<0105:WIAC>2.0 $\mathrm{CO} ; 2$

Cappelli S, Romano M, Buratti E. 2018. Systematic analysis of gene expression profiles controlled by hnRNP Q and hnRNP R, two closely related human RNA binding proteins implicated in mRNA processing mechanisms. Front Mol Biosci 5: 79. doi:10.3389/fmolb.2018 .00079

Carr AC, Khaled AS, Bassiouni R, Flores O, Nierenberg D, Bhatti H, Vishnubhotla P, Manuel JP, Santra S, Khaled AR. 2017. Targeting chaperonin containing TCP1 (CCT) as a molecular 
therapeutic for small cell lung cancer. Oncotarget 8: 110273 110288. doi:10.18632/oncotarget.22681

Chabot B, Shkreta L. 2016. Defective control of pre-messenger RNA splicing in human disease. J Cell Biol 212: 13-27. doi:10.1083/ jcb.201510032

Challagundla KB, Sun XX, Zhang X, DeVine T, Zhang Q, Sears RC, Dai MS. 2011. Ribosomal protein L11 recruits miR-24/miRISC to repress c-Myc expression in response to ribosomal stress. Mol Cell Biol 31: 4007-4021. doi:10.1128/MCB.05810-11

Chen B, Piel WH, Gui L, Bruford E, Monteiro A. 2005. The HSP90 family of genes in the human genome: insights into their divergence and evolution. Genomics 86: 627-637. doi:10.1016/j.ygeno .2005.08.012

Cheng HP, Liu Q, Li Y, Li XD, Zhu CY. 2017. The inhibitory effect of PDIA6 downregulation on bladder cancer cell proliferation and invasion. Oncol Res 25: 587-593. doi:10.3727/ $096504016 \times 14761811155298$

Chiluiza D, Bargo S, Callahan R, Rhoads RE. 2011. Expression of truncated eukaryotic initiation factor $3 e$ (elF3e) resulting from integration of mouse mammary tumor virus (MMTV) causes a shift from cap-dependent to cap-independent translation. J Biol Chem 286: 31288-31296. doi:10.1074/jbc.M111.267294

Chu C, Zhang QFC, da Rocha ST, Flynn RA, Bharadwaj M, Calabrese JM, Magnuson T, Heard E, Chang HY. 2015. Systematic discovery of Xist RNA binding proteins. Cell 161: 404-416. doi:10 .1016/j.cell.2015.03.025

Cobbold LC, Wilson LA, Sawicka K, King HA, Kondrashov AV, Spriggs KA, Bushell M, Willis AE. 2010. Upregulated c-myc expression in multiple myeloma by internal ribosome entry results from increased interactions with and expression of PTB-1 and YB-1. Oncogene 29: 2884-2891. doi:10.1038/onc.2010.31

Cook KB, Kazan H, Zuberi K, Morris Q, Hughes TR. 2011. RBPDB: a database of RNA-binding specificities. Nucleic Acids Res 39: D301-D308. doi:10.1093/nar/gkq1069

Coppin L, Leclerc J, Vincent A, Porchet N, Pigny P. 2018. Messenger RNA life-cycle in cancer cells: emerging role of conventional and non-conventional RNA-binding proteins? Int J Mol Sci 19: E650. doi:10.3390/ijms19030650

Corbett AH. 2018. Post-transcriptional regulation of gene expression and human disease. Curr Opin Cell Biol 52: 96-104. doi:10.1016/j .ceb.2018.02.011

Cowling VH. 2009. Regulation of mRNA cap methylation. Biochem J 425: 295-302. doi:10.1042/BJ20091352

Cox J, Mann M. 2008. MaxQuant enables high peptide identification rates, individualized p.p.b.-range mass accuracies and proteomewide protein quantification. Nat Biotechnol 26: 1367-1372. doi:10 .1038/nbt.1511

Cretu C, Schmitzová J, Ponce-Salvatierra A, Dybkov O, De Laurentiis El, Sharma K, Will CL, Urlaub H, Lührmann R, Pena V. 2016. Molecular architecture of SF3b and structural consequences of its cancer-related mutations. Mol Cell 64: 307-319. doi:10 .1016/j.molcel.2016.08.036

Dalgleish G, Veyrune JL, Blanchard JM, Hesketh J. 2001. mRNA localization by a 145-nucleotide region of the c-fos 3'-untranslated region. Links to translation but not stability. J Biol Chem 276: 13593 13599. doi:10.1074/jbc.M001141200

Dang CV. 2013. MYC, metabolism, cell growth, and tumorigenesis. Cold Spring Harb Perspect Med 3: a014217. doi:10.1101/cshper spect.a014217

Dardenne E, Polay Espinoza M, Fattet L, Germann S, Lambert MP, Neil H, Zonta E, Mortada H, Gratadou L, Deygas M, et al. 2014. RNA helicases DDX5 and DDX17 dynamically orchestrate transcription, miRNA, and splicing programs in cell differentiation. Cell Rep 7: 1900-1913. doi:10.1016/j.celrep.2014.05.010
Delaleau M, Borden KLB. 2015. Multiple export mechanisms for mRNAs. Cells 4: 452-473. doi:10.3390/cells4030452

Delgado MD, León J. 2010. Myc roles in hematopoiesis and leukemia. Genes Cancer 1: 605-616. doi:10.1177/1947601910377495

Deniz N, Lenarcic EM, Landry DM, Thompson SR. 2009. Translation initiation factors are not required for Dicistroviridae IRES function in vivo. RNA 15: 932-946. doi:10.1261/rna.1315109

Dobin A, Davis CA, Schlesinger F, Drenkow J, Zaleski C, Jha S, Batut P, Chaisson M, Gingeras TR. 2013. STAR: ultrafast universal RNA-seq aligner. Bioinformatics 29: 15-21. doi:10.1093/bioinformatics/ bts635

Eirin A, Riester SM, Zhu XY, Tang H, Evans JM, O'Brien D, van Wijnen AJ, Lerman LO. 2014. MicroRNA and mRNA cargo of extracellular vesicles from porcine adipose tissue-derived mesenchymal stem cells. Gene 551: 55-64. doi:10.1016/j.gene.2014.08 .041

The ENCODE Project Consortium. 2012. An integrated encyclopedia of DNA elements in the human genome. Nature 489: 57-74. doi:10.1038/nature11247

Erde J, Loo RR, Loo JA. 2014. Enhanced FASP (eFASP) to increase proteome coverage and sample recovery for quantitative proteomic experiments. J. Proteome Res 13: 1885-1895. doi:10.1021/ pr4010019

Evans JR, Mitchell SA, Spriggs KA, Ostrowski J, Bomsztyk K, Ostarek D, Willis AE. 2003. Members of the poly ( $\mathrm{rC}$ ) binding protein family stimulate the activity of the c-myc internal ribosome entry segment in vitro and in vivo. Oncogene 22: 8012-8020. doi:10 $.1038 /$ sj.onc. 1206645

Farrell $A S$, Joly $M M$, Allen-Petersen $B L$, Worth $P J$, Lanciault $C$, Sauer D, Link J, Pelz C, Heiser LM, Morton JP, et al. 2017. MYC regulates ductal-neuroendocrine lineage plasticity in pancreatic ductal adenocarcinoma associated with poor outcome and chemoresistance. Nat Commun 8: 1728. doi:10.1038/s41467-01701967-6

Gabay M, Li Y, Felsher DW. 2014. MYC activation is a hallmark of cancer initiation and maintenance. Cold Spring Harb Perspect Med 4: a014241. doi:10.1101/cshperspect.a014241

Gao H, Sun B, Fu H, Chi X, Wang F, Qi X, Hu J, Shao S. 2016. PDIA6 promotes the proliferation of HeLa cells through activating the Wnt/ $\beta$-catenin signaling pathway. Oncotarget 7: 53289-53298.

Garneau NL, Wilusz J, Wilusz CJ. 2007. The highways and byways of mRNA decay. Nat Rev Mol Cell Biol 8: 113-126. doi:10.1038/ nrm2104

The Gene Ontology Consortium. 2019. The Gene Ontology Resource: 20 years and still going strong. Nucleic Acids Res 47: D330-D338. doi:10.1093/nar/gky1055

George B, Horn D, Bayo P, Zaoui K, Flechtenmacher C, Grabe N, Plinkert P, Krizhanovsky V, Hess J. 2015. Regulation and function of Myb-binding protein 1A (MYBBP1A) in cellular senescence and pathogenesis of head and neck cancer. Cancer Lett 358: 191-199. doi:10.1016/j.canlet.2014.12.042

Geuens T, Bouhy D, Timmerman V. 2016. The hnRNP family: insights into their role in health and disease. Hum Genet 135: 851-867. doi:10.1007/s00439-016-1683-5

Ghosh M, Kemp M, Liu G, Ritzi M, Schepers A, Leffak M. 2006. Differential binding of replication proteins across the human cmyc replicator. Mol Cell Biol 26: 5270-5283. doi:10.1128/MCB .02137-05

Glisovic T, Bachorik JL, Yong J, Dreyfuss G. 2008. RNA-binding proteins and post-transcriptional gene regulation. FEBS Lett 582: 1977-1986. doi:10.1016/j.febslet.2008.03.004

González-Romero R, Eirín-López JM, Ausió J. 2015. Evolution of high mobility group nucleosome-binding proteins and its implications for vertebrate chromatin specialization. Mol Biol Evol 32: 121131. doi: $10.1093 / \mathrm{molbev} / \mathrm{msu} 280$ 
Gorgoni B, Gray NK. 2004. The roles of cytoplasmic poly(A)-binding proteins in regulating gene expression: a developmental perspective. Brief Funct Genomic Proteomic 3: 125-141. doi:10.1093/ bfgp/3.2.125

Haag C, Steuten B, Feldbrügge M. 2015. Membrane-coupled mRNA trafficking in fungi. Annu Rev Microbiol 69: 265-281. doi:10.1146/ annurev-micro-091014-104242

Halperin L, Jung J, Michalak M. 2014. The many functions of the endoplasmic reticulum chaperones and folding enzymes. IUBMB Life 66: 318-326. doi:10.1002/iub.1272

Hanley MB, Lomas W, Mittar D, Maino V, Park E. 2013. Detection of low abundance RNA molecules in individual cells by flow cytometry. PLOS ONE 8: e57002. doi:10.1371/journal.pone .0057002

Harshman SW, Young NL, Parthun MR, Freitas MA. 2013. H1 histones: current perspectives and challenges. Nucleic Acids Res 41: 95939609. doi:10.1093/nar/gkt700

Hausmann CD, Praetorius-lbba M, Ibba M. 2007. An aminoacyl-tRNA synthetase: elongation factor complex for substrate channeling in archaeal translation. Nucleic Acids Res 35: 6094-6102. doi:10 $.1093 / \mathrm{nar} / \mathrm{gkm} 534$

Heidelberger JB, Voigt A, Borisova ME, Petrosino G, Ruf S, Wagner SA, Beli P. 2018. Proteomic profiling of VCP substrates links VCP to K6-linked ubiquitylation and c-Myc function. EMBO Rep 19: e44754. doi:10.15252/embr.201744754

Henikoff S, Smith MM. 2015. Histone variants and epigenetics. Cold Spring Harb Perspect Biol 7: a019364. doi:10.1101/cshperspect .a019364

Hesketh JE, Campbell GP, Whitelaw PF. 1991. c-myc mRNA in cytoskeletal-bound polysomes in fibroblasts. Biochem J 274: 607609. doi:10.1042/bj2740607

Hong K. 2018. Emerging function of N6-methyladenosine in cancer. Oncol Lett 16: 5519-5524. doi:10.3892/ol.2018.9395

Horos R, ljspeert H, Pospisilova D, Sendtner R, Andrieu-Soler C, Taskesen E, Nieradka A, Cmejla R, Sendtner M, Touw IP, et al. 2012. Ribosomal deficiencies in Diamond-Blackfan anemia impair translation of transcripts essential for differentiation of murine and human erythroblasts. Blood 119: 262-272. doi:10.1182/blood2011-06-358200

Hsu FM, Zhang S, Chen BPC. 2012. Role of DNA-dependent protein kinase catalytic subunit in cancer development and treatment. Transl Cancer Res 1: 22-34.

Ideue T, Azad AK, Yoshida J, Matsusaka T, Yanagida M, Ohshima Y, Tani T. 2004. The nucleolus is involved in mRNA export from the nucleus in fission yeast. J Cell Sci 117: 2887-2895. doi:10.1242/ jcs.01155

Jankowsky E, Harris M E. 2015. Specificity and nonspecificity in RNAprotein interactions. Nat Rev Mol Cell Biol 16: 533-544. doi:10 $.1038 / \mathrm{nrm} 4032$

Jansen RP, Niessing D, Baumann S, Feldbrügge M. 2014. mRNA transport meets membrane traffic. Trends Genet 30: 408-417. doi:10.1016/j.tig.2014.07.002

Johnson AG, Grosely R, Petrov AN, Puglisi JD. 2017. Dynamics of IRES-mediated translation. Philos Trans $R$ Soc Lond B Biol Sci 372: 20160177 . doi:10.1098/rstb.2016.0177

Jolles B, Aliouat A, Stierlé V, Salhi S, Jean-Jean O. 2018. Translation termination-dependent deadenylation of MYC mRNA in human cells. Oncotarget 9: 26171-26182. doi:10.18632/oncotarget .25459

Kabachinski G, Schwartz TU. 2015. The nuclear pore complex-structure and function at a glance. J Cell Sci 128: 423-429. doi:10 $.1242 /$ jcs.083246

Kalkat M, De Melo J, Hickman KA, Lourenco C, Redel C, Resetca D, Tamachi A, Tu WB, Penn LZ. 2017. MYC deregulation in primary human cancers. Genes (Basel) 8: E151. doi:10.3390/ genes 8060151

Kampen KR, Sulima SO, Verbelen B, Girardi T, Vereecke S, Rinaldi G, Verbeeck J, Op de Beeck J, Uyttebroeck A, Meijerink JPP, et al. 2019. The ribosomal RPL10 R98S mutation drives IRES-dependent BCL-2 translation in T-ALL. Leukemia 33: 319-332. doi:10.1038/ s41375-018-0176-z

Ke S, Pandya-jones A, Saito Y, Fak JJ, Vågbø CB, Geula S, Hanna JH, Black DL, Darnel JE Jr, Darnell RB. 2017. m A mRNA modifications are deposited in nascent pre-mRNA and are not required for splicing but do specify cytoplasmic turnover. Genes Dev 31: 9901006. doi:10.1101/gad.301036.117

Kechavarzi B, Janga SC. 2014. Dissecting the expression landscape of RNA-binding proteins in human cancers. Genome Biol 15: R14. doi:10.1186/gb-2014-15-1-r14

Keene JD. 2007. RNA regulons: coordination of post-transcriptional events. Nat Rev Genet 8: 533-543. doi:10.1038/nrg2111

Keene JD, Tenenbaum SA. 2002. Eukaryotic mRNPs may represent post transcriptional operons. Mol Cell 9: 1161-1167. doi:10 .1016/S1097-2765(02)00559-2

Kim JH, Paek KY, Choi K, Kim TD, Hahm B, Kim KT, Jang SK. 2003. Heterogeneous nuclear ribonucleoprotein $C$ modulates translation of c-myc mRNA in a cell cycle phase-dependent manner. Mol Cell Biol 23: 708-720. doi:10.1128/MCB.23.2.708-720.2003

Kim HH, Kuwano Y, Srikantan S, Lee EK, Martindale JL, Gorospe M. 2009. HuR recruits let-7/RISC to repress c-Myc expression. Genes Dev 23: 1743-1748. doi:10.1101/gad.1812509

Knoener RA, Becker JT, Scalf M, Sherer NM, Smith LM. 2017. Elucidating the in vivo interactome of HIV-1 RNA by hybridization capture and mass spectrometry. Sci Rep 7: 16965. doi:10.1038/ s41598-017-16793-5

Koh CM, Sabo A, Guccione E. 2016. Targeting MYC in cancer therapy: RNA processing offers new opportunities. Bioessays 38: 266-275. doi:10.1002/bies.201500134

Köhler A, Hurt E. 2007. Exporting RNA from the nucleus to the cytoplasm. Nat Rev Mol Cell Biol 8: 761-773. doi:10.1038/nrm2255

Kumar GR, Glaunsinger BA. 2010. Nuclear import of cytoplasmic poly (A) binding protein restricts gene expression via hyperadenylation and nuclear retention of mRNA. Mol Cell Biol 30: 4996-5008. doi:10.1128/MCB.00600-10

Laird-Offringa IA, Elfferich P, Knaken HJ, de Ruiter J, van der Eb AJ. 1989. Analysis of polyadenylation site usage of the c-myc oncogene. Nucleic Acids Res 17: 6499-6514. doi:10.1093/nar/17.16 .6499

Langa F, Lafon I, Vandormael-Pournin S, Vidaud M, Babinet C, Morello D. 2001. Healthy mice with an altered c-myc gene: role of the $3^{\prime}$ untranslated region revisited. Oncogene 20: 43444353. doi:10.1038/sj.onc. 1204482

Lee K, Hsiung CC, Huang P, Raj A, Blobel GA. 2015. Dynamic enhancer-gene body contacts during transcription elongation. Genes Dev 29: 1992-1997. doi:10.1101/gad.255265.114

Lemaire R, Prasad J, Kashima T, Gustafson J, Manley JL, Lafyatis R. 2002. Stability of a PKCl-1-related mRNA is controlled by the splicing factor ASF/SF2: a novel function for SR proteins. Genes Dev 16: 594-607. doi:10.1101/gad.939502

Lemm I, Ross J. 2002. Regulation of c-myc mRNA decay by translational pausing in a coding region instability determinant. Mol Cell Biol 22: 3959-3969. doi:10.1128/MCB.22.12.3959-3969 .2002

Li B, Dewey CN. 2011. RSEM: accurate transcript quantification from RNA-seq data with or without a reference genome. BMC Bioinformatics 12: 323. doi:10.1186/1471-2105-12-323

Li M, Liu Y. 2016. Topoisomerase I in human disease pathogenesis and treatments. Genomics Proteomics Bioinformatics 14: 166171. doi:10.1016/j.gpb.2016.02.004 
Li D, Wei T, Abbott CM, Harrich D. 2013. The unexpected roles of eukaryotic translation elongation factors in RNA virus replication and pathogenesis. Microbiol Mol Biol Rev 77: 253-266. doi:10.1128/ MMBR.00059-12

Li J, Hu YM, Du YJ, Zhu LR, Qian H, Wu Y, Shi WL. 2014. Expressions of MUC1 and vascular endothelial growth factor mRNA in blood are biomarkers for predicting efficacy of gefitinib treatment in nonsmall cell lung cancer. BMC Cancer 14: 848. doi:10.1186/14712407-14-848

Li W, You B, Hoque M, Zheng D, Luo W, Ji Z, Park JY, Gunderson SI, Kalsotra A, Manley JL, et al. 2015. Systematic profiling of poly(A) ${ }^{+}$ transcripts modulated by core $3^{\prime}$ end processing and splicing factors reveals regulatory rules of alternative cleavage and polyadenylation. PLoS Genet 11: e1005166. doi:10.1371/journal.pgen 1005166

Li XL, Subramanian M, Jones MF, Chaudhary R, Singh DK, Zong X, Gryder B, Sindri S, Mo M, Schetter A, et al. 2017. Long noncoding RNA PURPL suppresses basal p53 levels and promotes tumorigenicity in colorectal cancer. Cell Rep 20: 2408-2423. doi:10.1016/j .celrep.2017.08.041

Liao JM, Zhou X, Gatignol A, Lu H. 2014. Ribosomal proteins L5 and L11 co-operatively inactivate c-Myc via RNA-induced silencing complex. Oncogene 33: 4916-4923. doi:10.1038/onc.2013.430

Liu L, Ouyang M, Rao JN, Zou T, Xiao L, Chung HK, Wu J, Donahue JM, Gorospe M, Wang JY. 2015. Competition between RNA-binding proteins CELF1 and HuR modulates MYC translation and intestinal epithelium renewal. Mol Biol Cell 26: 1797-1810. doi:10.1091/mbc.E14-11-1500

Long JC, Caceres JF. 2009. The SR protein family of splicing factors: master regulators of gene expression. Biochem J 417: 15-27. doi:10.1042/BJ20081501

López-Lastra M, Rivas A, Barría MI. 2005. Protein synthesis in eukaryotes: the growing biological relevance of cap-independent translation initiation. Biol Res 38: 121-146. doi:10.4067/S071697602005000200003

Mangus DA, Evans ME, Jacobso A. 2003. Poly(A)-binding proteins: multifunctional scaffolds for the posttranscriptional control of gene expression. Genome Biol 4: 223. doi:10.1186/gb-2003-47-223

Marchese D, de Groot NS, Lorenzo Gotor N, Livi CM, Tartaglia GG. 2016. Advances in the characterization of RNA-binding proteins. Wiley Interdiscip Rev RNA 7: 793-810. doi:10.1002/wrna.1378

Matassa DS, Agliarulo I, Amoroso MR, Maddalena F, Sepe L, Ferrari MC, Sagar V, D'Amico S, Loreni F, Paolella G, et al. 2014. TRAP1-dependent regulation of p70S6K is involved in the attenuation of protein synthesis and cell migration: relevance in human colorectal tumors. Mol Oncol 8: 1482-1494. doi:10.1016/j .molonc.2014.06.003

McHugh CA, Chen CK, Chow A, Surka CF, Tran C, McDonel P, Pandya-Jones A, Blanco M, Burghard C, Moradian A, et al. 2015. The Xist IncRNA interacts directly with SHARP to silence transcription through HDAC3. Nature 521: 232-236. doi:10 $.1038 /$ nature 14443

McLeod T, Abdullahi A, Li M, Brogna S. 2014. Recent studies implicate the nucleolus as the major site of nuclear translation. Biochem Soc Trans 42: 1224-1228. doi:10.1042/BST20140062

Mollaoglu G, Guthrie MR, Böhm S, Brägelmann J, Can I, Ballieu PM, Marx A, George J, Heinen C, Chalishazar MD, et al. 2017. MYC drives progression of small cell lung cancer to a variant neuroendocrine subtype with vulnerability to aurora kinase inhibition. Cancer Cell 31: 270-285. doi:10.1016/j.ccell.2016.12.005

Monie TP, Perrin AJ, Birtley JR, Sweeney TR, Karakasiliotis I, Chaudhry Y, Roberts LO, Matthews S, Goodfellow IG, Curry S. 2007. Structural insights into the transcriptional and translational roles of Ebp1. EMBO J 26: 3936-3944. doi:10.1038/sj.emboj .7601817

Monteiro FL, Baptista T, Amado F, Vitorino R, Jerónimo C, Helguero LA. 2014. Expression and functionality of histone H2A variants in cancer. Oncotarget 5: 3428-3443. doi:10.18632/onco target.2007

Mora A, Sandve GK, Gabrielsen OS, Eskeland R. 2016. In the loop: promoter-enhancer interactions and bioinformatics. Brief Bioinform 17: 980-995. doi:10.1093/bib/bbv097

Mori S, Bernardi R, Laurent A, Resnati M, Crippa A, Gabrieli A, Keough R, Gonda TJ, Blasi F. 2012. Myb-binding protein 1A (MYBBP1A) is essential for early embryonic development, controls cell cycle and mitosis, and acts as a tumor suppressor. PLoS One 7: e39723. doi:10.1371/journal.pone.0039723

Müller-McNicoll M, Botti $V$, de Jesus Domingues AM, Brandl $H$, Schwich OD, Steiner MC, Curk T, Poser I, Zarnack K, Neugebauer KM. 2016. SR proteins are NXF1 adaptors that link alternative RNA processing to mRNA export. Genes Dev 30: 553566. doi:10.1101/gad.276477.115

Murakami K, Nakano K, Shimizu T, Ohto U. 2017. The crystal structure of human DEAH-box RNA helicase 15 reveals a domain organization of the mammalian DEAH/RHA family. Acta Crystallogr F Struct Biol Commun 73: 347-355. doi:10.1107/S2053230X17007336

Narayanan A, Pullepu D, Kabir MA. 2016. The interactome of CCT complex-a computational analysis. Comput Biol Chem 64: 396-402. doi:10.1016/j.compbiolchem.2016.09.002

Naro C, Bielli P, Pagliarini V, Sette C. 2015. The interplay between DNA damage response and RNA processing: the unexpected role of splicing factors as gatekeepers of genome stability. Front Genet 6: 142. doi:10.3389/fgene.2015.00142

Neve J, Patel R, Wang Z, Louey A, Furger AM. 2017. Cleavage and polyadenylation: ending the message expands gene regulation. RNA Biol 14: 865-890. doi:10.1080/15476286.2017.1306171

Nguyen le XT, Zhu L, Lee Y, Ta L, Mitchell BS. 2016. Expression and role of the ErbB3-binding protein 1 in acute myelogenous leukemic cells. Clin Cancer Res 22: 3320-3327. doi:10.1158/10780432.CCR-15-2282

Nissen KE, Homer CM, Ryan CJ, Shales M, Krogan NJ, Patrick KL, Guthrie C. 2017. The histone variant H2A.Z promotes splicing of weak introns. Genes Dev 31: 688-701. doi:10.1101/gad.295287 .116

Nolan T, Hands RE, Bustin SA. 2006. Quantification of mRNA using real-time RT-PCR. Nat Protoc 1: 1559-1582. doi:10.1038/nprot .2006 .236

Ogami K, Hosoda N, Funakoshi Y, Hoshino S. 2014. Antiproliferative protein Tob directly regulates c-myc proto-oncogene expression through cytoplasmic polyadenylation element-binding protein CPEB. Oncogene 33: 55-64. doi:10.1038/onc.2012.548

Orrù S, Aspesi A, Armiraglio M, Caterino M, Loreni F, Ruoppolo M, Santoro C, Dianzani I. 2007. Analysis of the ribosomal protein S19 interactome. Mol Cell Proteomics 6: 382-393. doi:10.1074/ mcp.M600156-MCP200

Oughtred R, Stark C, Breitkreutz BJ, Rust J, Boucher L, Chang C, Kolas N, O'Donnell L, Leung G, McAdam R, et al. 2019. The BioGRID interaction database: 2019 update. Nucleic Acids Res 47: D529-D541. doi:10.1093/nar/gky1079

Pallavicini MG, George T, Deteresa PS, Amendola R, Gray JW. 1994. Intracellular dynamics of c-myc mRNA traffic in single cells in situ. $J$ Cell Physiol 158: 223-230. doi:10.1002/jcp.1041580203

Paz I, Kosti I, Ares M Jr, Cline M, Mandel-Gutfreund Y. 2014. RBPmap: a web server for mapping binding sites of RNA-binding proteins. Nucleic Acids Res 42: W361-W367. doi:10.1093/nar/gku406

Pinz S, Unser S, Rascle A. 2016. Signal transducer and activator of transcription STAT5 is recruited to c-Myc super-enhancer. BMC Mol Biol 17: 10. doi:10.1186/s12867-016-0063-y 
Rangasamy D. 2010. Histone variant H2A.Z can serve as a new target for breast cancer therapy. Curr Med Chem 17: 3155-3161. doi:10 .2174/092986710792231941

Rissland OS. 2017. The organization and regulation of mRNA-protein complexes. WileyInterdiscip Rev RNA 8: e1369. doi:10.1002/wrna .1369

Ryder SP. 2016. Protein-mRNA interactome capture: cartography of the mRNP landscape. F1000Res 5: 2627. doi:10.12688/f1000re search.9404.1

Saibil H. 2013. Chaperone machines for protein folding, unfolding and disaggregation. Nat Rev Mol Cell Biol 14: 630-642. doi:10 $.1038 / \mathrm{nrm} 3658$

Sanders JA, Gruppuso PA. 2005. Nucleolar localization of hepatic cMyc: a potential mechanism for c-Myc regulation. Biochim Biophys Acta 1743: 141-150. doi:10.1016/j.bbamcr.2004.09.009

Santisteban MS, Hang M, Smith MM. 2011. Histone variant H2A.Z and RNA polymerase II transcription elongation. Mol Cell Biol 31: 1848-1860. doi:10.1128/MCB.01346-10

Sato-Kuwabara Y, Melo SA, Soares FA, Calin GA. 2015. The fusion of two worlds: non-coding RNAs and extracellular vesicles-diagnostic and therapeutic implications. Int J Oncol 46: 17-27. doi:10 .3892/ijo.2014.2712

Scherl A, Couté Y, Déon C, Callé A, Kindbeiter K, Sanchez JC, Greco A, Hochstrasser D, Diaz JJ. 2002. Functional proteomic analysis of human nucleolus. Mol Biol Cell 13: 4100-4109. doi:10.1091/mbc.e02-05-0271

Sears RC. 2004. The life cycle of C-myc: from synthesis to degradation. Cell Cycle 3: 1133-1137.

Selvatici R, Boninsegna S, Ferrati M, Gandini E. 1998. Nuclear accumulation of c-myc mRNA in phytohaemagglutinin-activated T lymphocytes treated with anti-HLA class I monoclonal antibody. FEBS Lett 421: 50-54. doi:10.1016/S0014-5793(97)01524-X

Shi Y, Di Giammartino DC, Taylor D, Sarkeshik A, Rice WJ, Yates JR III, Frank J, Manley JL. 2009. Molecular architecture of the human premRNA 3' processing complex. Mol Cell 33: 365-376. doi:10.1016/ j.molcel.2008.12.028

Shi Y, Yang Y, Hoang B, Bardeleben C, Holmes B, Gera J, Lichtenstein A. 2016. Therapeutic potential of targeting IRES-dependent c-myc translation in multiple myeloma cells during ER stress. Oncogene 35: 1015-1024. doi:10.1038/onc.2015.156

Shimizu N, Kawamoto J, Utani K. 2007. Regulation of c-myc through intranuclear localization of its RNA subspecies. Biochem Biophys Res Commun 359: 806-810. doi:10.1016/j.bbrc.2007.05.201

Simone LE, Keene JD. 2013. Mechanisms coordinating ELAV/Hu mRNA regulons. Curr Opin Genet Dev 23: 35-43. doi:10.1016/j gde.2012.12.006

Singh H, Lane AA, Correll M, Przychodzen B, Sykes DB, Stone RM, Ballen KK, Amrein PC, Maciejewski J, Attar EC. 2013. Putative RNA-splicing gene LUC7L2 on 7q34 represents a candidate gene in pathogenesis of myeloid malignancies. Blood Cancer $J$ 3: e117. doi:10.1038/bcj.2013.16

Singh G, Pratt G, Yeo GW, Moore MJ. 2015. The clothes make the mRNA: past and present trends in mRNP fashion. Annu Rev Biochem 84: 325-354. doi:10.1146/annurev-biochem-080111092106

Siprashvili Z, Webster DE, Kretz M, Johnston D, Rinn JL, Chang HY, Khavari PA. 2012. Identification of proteins binding coding and non-coding human RNAs using protein microarrays. BMC Genomics 13: 633. doi:10.1186/1471-2164-13-633

Snyder M, Huang X, Zhang JJ. 2009. The minichromosome maintenance proteins 2-7 (MCM2-7) are necessary for RNA polymerase II (Pol II)-mediated transcription. J Biol Chem 284: 1346613472. doi:10.1074/jbc.M809471200

Soung YH, Ford S, Zhang V, Chung J. 2017. Exosomes in cancer diagnostics. Cancers (Basel) 9: 8. doi:10.3390/cancers9010008
Speese SD, Ashley J, Jokhi V, Nunnari J, Barria R, Li Y, Ataman B, Koon A, Chang YT, Li Q, et al. 2012. Nuclear envelope budding enables large ribonucleoprotein particle export during synaptic Wnt signaling. Cell 149: 832-846. doi:10.1016/j.cell.2012.03.032

Spiniello M, Knoener RA, Steinbrink MI, Yang B, Cesnik AJ, Buxton KE, Scalf M, Jarrard DF, Smith LM. 2018. HyPR-MS for multiplexed discovery of MALAT1, NEAT1, and NORAD IncRNA protein interactomes. J Proteome Res 17: 3022-3038. doi:10.1021/ acs.jproteome.8b00189

Stepanova L, Finegold M, DeMayo F, Schmidt EV, Harper JW. 2000. The oncoprotein kinase chaperone CDC37 functions as an oncogene in mice and collaborates with both c-myc and cyclin D1 in transformation of multiple tissues. Mol Cell Biol 20: 4462-4473. doi:10.1128/MCB.20.12.4462-4473.2000

Stoneley M, Subkhankulova T, Le Quesne JP, Coldwell MJ, Jopling CL, Belsham GJ, Willis AE. 2000. Analysis of the c-myc IRES; a potential role for cell-type specific trans-acting factors and the nuclear compartment. Nucleic Acids Res 28: 687-694. doi:10.1093/nar/28.3.687

Strambio-De-Castilla C. 2013. Jumping over the fence: RNA nuclear export revisited. Nucleus 4: 95-99. doi:10.4161/nucl.24237

Su R, Dong L, Li C, Nachtergaele S, Wunderlich M, Qing Y, Deng X, Wang Y, Weng X, Hu C, et al. 2018. R-2HG exhibits anti-tumor activity by targeting $\mathrm{FTO} / \mathrm{m}^{6} \mathrm{~A} / \mathrm{MYC} / \mathrm{CEBPA}$ signaling. Cell 172: 90 105.e23. doi:10.1016/j.cell.2017.11.031

Sun D, Novotny M, Bulek K, Liu C, Li X, Hamilton T. 2011. Treatment with IL-17 prolongs the half-life of chemokine CXCL1 mRNA via the adaptor TRAF5 and the splicing-regulatory factor SF2 (ASF). Nat Immunol 12: 853-860. doi:10.1038/ni.2081

Szklarczyk D, Morris JH, Cook H, Kuhn M, Wyder S, Simonovic M, Santos A, Doncheva NT, Roth A, Bork P, et al. 2017. The STRING database in 2017: quality-controlled protein-protein association networks, made broadly accessible. Nucleic Acids Res 45: D362-D368. doi:10.1093/nar/gkw937

Talbert PB, Henikoff S. 2017. Histone variants on the move: substrates for chromatin dynamics. Nat Rev Mol Cell Biol 18: 115-126. doi:10 $.1038 / \mathrm{nrm} .2016 .148$

Tansey WP. 2014. Mammalian MYC proteins and cancer. New J Sci 2014: 1-27. doi:10.1155/2014/757534

Thoma C, Fraterman S, Gentzel M, Wilm M, Hentze MW. 2008. Translation initiation by the c-myc mRNA internal ribosome entry sequence and the poly(A) tail. RNA 14: 1579-1589. doi:10 $.1261 /$ rna.1043908

Tolstorukov MY, Goldman JA, Gilbert C, Ogryzko V, Kingston RE, Park PJ. 2012. Histone variant H2A.Bbd is associated with active transcription and mRNA processing in human cells. Mol Cell 47: 596-607. doi:10.1016/j.molcel.2012.06.011

Trixl L, Lusser A. 2018. The dynamic RNA modification 5-methylcytosine and its emerging role as an epitranscriptomic mark. Wiley Interdiscip Rev RNA 10: e1510. doi:10.1002/wrna.1510

The Uniprot Consortium. 2019. Uniprot: a worldwide hub of protein knowledge. Nucleic Acids Res 47: D506-D515. doi:10.1093/nar/ gky1049

Vaklavas C, Meng Z, Choi H, Grizzle WE, Zinn KR, Blume SW. 2015. Small molecule inhibitors of IRES-mediated translation. Cancer Biol Ther 16: 1471-1485. doi:10.1080/15384047.2015.1071729

van de Waterbeemd M, Tamara S, Fort KL, Damoc E, Franc V, Bieri P, Itten M, Makarov A, Ban N, Heck AJR. 2018. Dissecting ribosomal particles throughout the kingdoms of life using advanced hybrid mass spectrometry methods. Nat Commun 9: 2493. doi:10 1038/s41467-018-04853-x

van Kouwenhove M, Kedde M, Agami R. 2011. MicroRNA regulation by RNA-binding proteins and its implications for cancer. Nat Rev Cancer 11: 644-656. doi:10.1038/nrc3107 
Vaqué JP, Navascues J, Shiio Y, Laiho M, Ajenjo N, Mauleon I, Matallanas D, Crespo P, León J. 2005. Myc antagonizes Ras-mediated growth arrest in leukemia cells through the inhibition of the Ras-ERK-p21 Cip1 pathway. J Biol Chem 280: 1112-1122. doi:10 .1074/jbc.M409503200

Warneboldt J, Haller F, Horstmann O, Danner BC, Füzesi L, Doenecke D, Happel N. 2008. Histone H1x is highly expressed in human neuroendocrine cells and tumours. BMC Cancer 8: 388. doi:10.1186/1471-2407-8-388

Weidensdorfer D, Stohr N, Baude A, Lederer M, Kohn M, Schierhorn A, Buchmeier S, Wahle E, Huttelmaier S. 2009. Control of c-myc mRNA stability by IGF2BP1-associated cytoplasmic RNPs. RNA 15: 104-115. doi:10.1261/rna.1175909

West JA, Davis CP, Sunwoo H, Simon MD, Sadreyev RI, Wang PI, Tolstorukov MY, Kingston RE. 2014. The long noncoding RNAs NEAT1 and MALAT1 bind active chromatin sites. Mol Cell 55: 791-802. doi:10.1016/j.molcel.2014.07.012

Wiegering $A$, Uthe FW, Jamieson $T$, Ruoss $Y$, Huttenrauch $M$, Kuspert M, Pfann C, Nixon C, Herold S, Walz S, et al. 2015. Targeting translation initiation bypasses signaling crosstalk mechanisms that maintain high MYC levels in colorectal cancer. Cancer Discov 5: 768-781. doi:10.1158/2159-8290.CD-14-1040

Wierstra I, Alves J. 2008. The c-myc promoter: still MysterY and challenge. Adv Cancer Res 99: 113-333. doi:10.1016/S0065-230X(07) 99004-1

Will CL, Lührmann R. 2011. Spliceosome structure and function. Cold Spring Harb Perspect Biol 3: a003707. doi:10.1101/cshperspect .a003707

Yamauchi T, Keough RA, Gonda TJ, Ishii S. 2008. Ribosomal stress induces processing of Mybbp1a and its translocation from the nucleolus to the nucleoplasm. Genes Cells 13: 27-39. doi:10.1111/j .1365-2443.2007.01148.x

Yang L, Qiu J, Xiao Y, Hu X, Liu Q, Chen L, Huang W, Li X, Li L, Zhang J, et al. 2018a. AP-2 $\beta$ inhibits hepatocellular carcinoma invasion and metastasis through Slug and Snail to suppress epithelial-mesenchymal transition. Theranostics 8: 3707-3721. doi:10.7150/thno .25166

Yang K, Jie Yang J, Yi J. 2018b. Nucleolar stress: hallmarks, sensing mechanism and diseases. Cell Stress 2: 125-140. doi:10.15698/ cst2018.06.139
Yi R, Bogerd HP, Wiegand HL, Cullen BR. 2002. Both ran and importins have the ability to function as nuclear mRNA export factors. RNA 8: 180-187. doi:10.1017/S1355838202012384

Yun JJ, Heisler LE, Hwang II, Wilkins O, Lau SK, Hyrcza M, Jayabalasingham B, Jin J, McLaurin J, Tsao MS, et al. 2006. Genomic DNA functions as a universal external standard in quantitative real-time PCR. Nucleic Acids Res 34: e85. doi:10.1093/nar/ gkl400

Zhang D, Shan SO. 2012. Translation elongation regulates substrate selection by the signal recognition particle. J Biol Chem 287: 7652-7660. doi:10.1074/jbc.M111.325001

Zhang D, Abovich N, Rosbash M. 2001. A biochemical function for the Sm complex. Mol Cell 7: 319-329. doi:10.1016/S1097-2765(01) 00180-0

Zhang Z, Theler D, Kaminska KH, Hiller M, de la Grange P, Pudimat R, Rafalska I, Heinrich B, Bujnicki JM, Allain FH, et al. 2010. The YTH domain is a novel RNA binding domain. J Biol Chem 285: 1470114710. doi:10.1074/jbc.M110.104711

Zhang Y, O'Leary MN, Peri S, Wang M, Zha J, Melov S, Kappes DJ, Feng Q, Rhodes J, Amieux PS, et al. 2017. Ribosomal proteins Rpl22 and Rpl22l1 control morphogenesis by regulating premRNA splicing. Cell Rep 18: 545-556. doi:10.1016/j.celrep.2016 .12 .034

Zheng M, Cierpicki T, Burdette AJ, Utepbergenov D, Janczyk PŁ, Derewenda U, Stukenberg PT, Caldwell KA, Derewenda ZS. 2011. Structural features and chaperone activity of the NudC protein family. J Mol Biol 409: 722-741. doi:10.1016/j.jmb.2011.04 .018

Zhong W, Li Z, Zhou M, Xu T, Wang Y. 2018. DDX1 regulates alternative splicing and insulin secretion in pancreatic $\beta$ cells. Biochem Biophys Res Commun 500: 751-757. doi:10.1016/j.bbrc.2018 .04 .147

Zhou X, Hao Q, Liao JM, Liao P, Lu H. 2013. Ribosomal protein S14 negatively regulates c-Myc activity. J Biol Chem 288: $21793-$ 21801. doi:10.1074/jbc.M112.445122

Zhou Z, Patel M, Ng N, Hsieh MH, Orth AP, Walker JR, Batalov S, Harris JL, Liu J. 2014. Identification of synthetic lethality of PRKDC in MYC-dependent human cancers by pooled shRNA screening. BMC Cancer 14: 944. doi:10.1186/1471-2407-14-944 

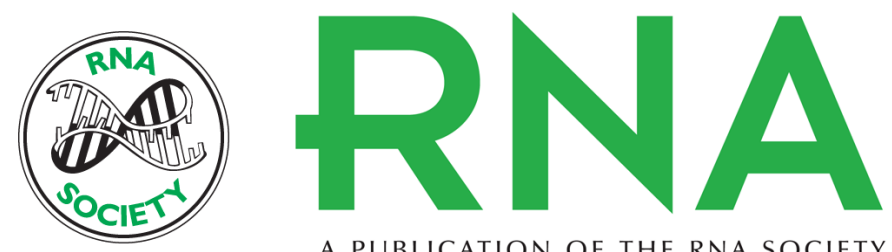

A PUBLICATION OF THE RNA SOCIETY

\section{Comprehensive in vivo identification of the c-Myc mRNA protein interactome using HyPR-MS}

Michele Spiniello, Maisie I. Steinbrink, Anthony J. Cesnik, et al.

RNA 2019 25: 1337-1352 originally published online July 11, 2019

Access the most recent version at doi:10.1261/rna.072157.119

\section{Supplemental http://rnajournal.cshlp.org/content/suppl/2019/07/11/rna.072157.119.DC1 Material}

References This article cites 184 articles, 47 of which can be accessed free at: http://rnajournal.cshlp.org/content/25/10/1337.full.html\#ref-list-1

Open Access Freely available online through the RNA Open Access option.

Creative This article, published in $R N A$, is available under a Creative Commons License Commons (Attribution 4.0 International), as described at

License http://creativecommons.org/licenses/by/4.0/.

Email Alerting Receive free email alerts when new articles cite this article - sign up in the box at the Service top right corner of the article or click here.

\section{|||||||| Providing Precise Solutions for} your research.

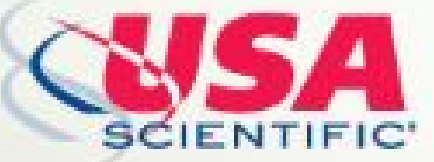

To subscribe to $R N A$ go to:

http://rnajournal.cshlp.org/subscriptions

(C) 2019 Spiniello et al.; Published by Cold Spring Harbor Laboratory Press for the RNA Society 